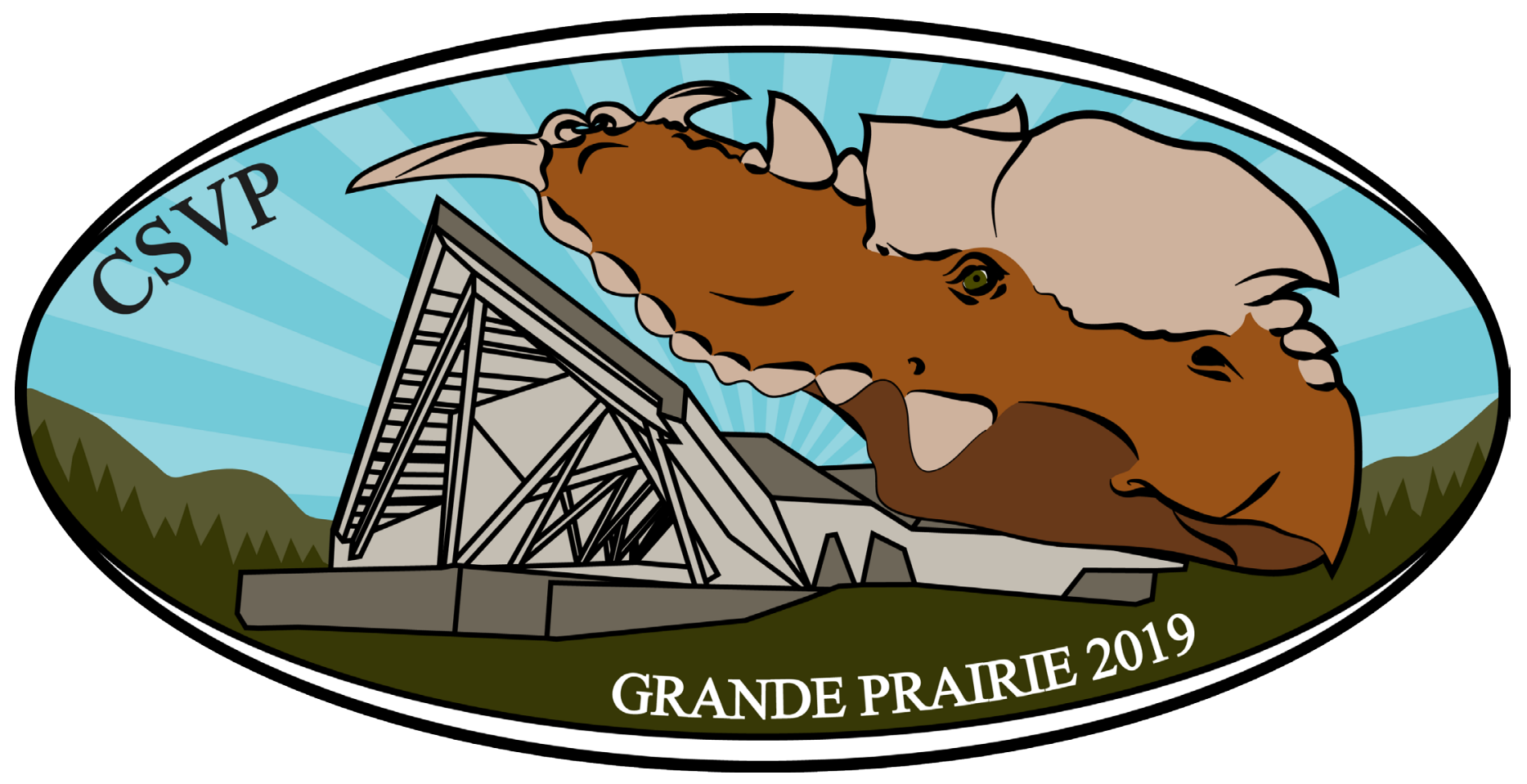




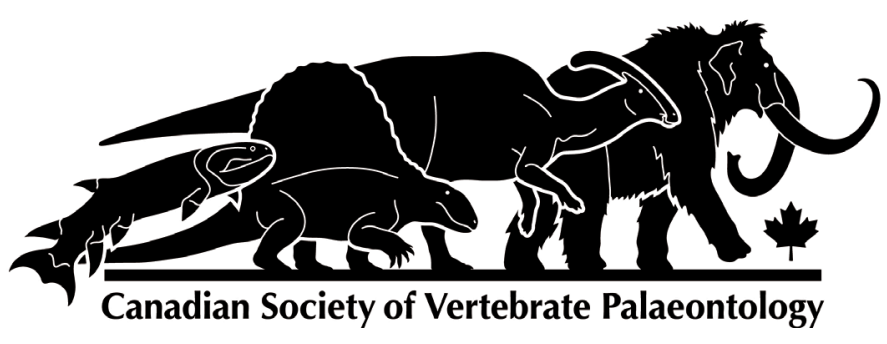

Published 2 May, 2019

Editors: Alison M. Murray, Aaron LeBlanc and Robert

Meeting Logo Design: Robin Sissons

\section{B. Holmes}

(C) 2019 by the authors

\section{DOI 10.18435/vamp29349}

Vertebrate Anatomy Morphology Palaeontology is an open access journal http://ejournals.library.ualberta.ca/index.php/VAMP Article copyright by the author(s). This open access work is distributed under a Creative

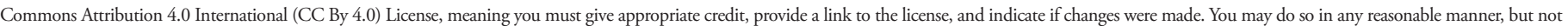
in any way that suggests the licensor endorses you or your use. No additional restrictions - You may not apply legal terms or technological measures that legally restrict others from doing anything the license permits. 


\section{$7^{\text {th }}$ Annual Meeting}

Canadian Society of

Vertebrate Palaeontology

May 10-13, 2019

Grande Prairie, Alberta

Abstracts 


\section{Host Committee}

Lisa Buckley, Director, Peace Region Palaeontology Research Centre

Derek Larson, Assistant Curator, Philip J. Currie Dinosaur Museum

Aaron LeBlanc, NSERC Postdoctoral Fellow, Department of Biological Sciences, University of Alberta

Rich McCrea, Adjunct Researcher, Peace Region Palaeontology Research Centre

Corwin Sullivan, Philip J. Currie Professor of Vertebrate Palaeontology, Department of Biological Sciences, University of Alberta and Curator, Philip J. Currie Dinosaur Museum

Matthew Vavrek, Cutbank Palaeontological Consulting

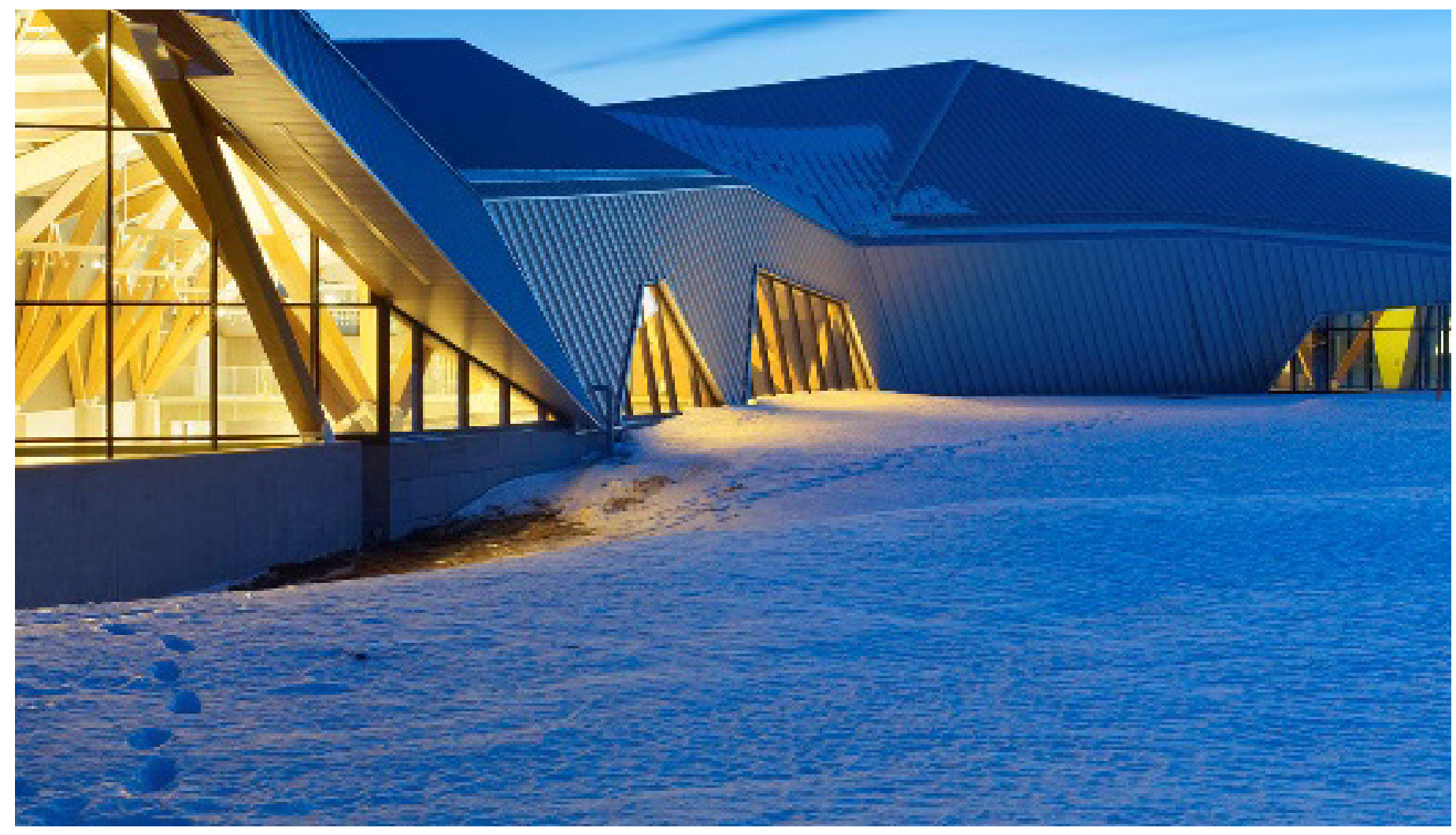


A Maastrichtian-aged leptoceratopsid from the Sustut River, northern BC, and potential for new vertebrate fossil discoveries in the Sustut Basin

Victoria M. Arbour, David C. Evans, D. Jade Simon, and Thomas M. Cullen

The Triceratops 'Baby Book': An update on juvenile ceratopsians from the Frenchman Formation of Saskatchewan, Canada

Emily L. Bamforth

Campanian conundrum: Large-scale spatial diversity patterns elucidate Judith River and Dinosaur Park

Formation equivalents in Saskatchewan, Canada

Emily L. Bamforth ${ }^{1}$ and Meagan M. Gilbert

Latest Cretaceous climate proxies using carbon and hydrogen isotopes from plant wax-lipids

Robert D. Bourque, Peter Douglas, and Hans C.E. Larsson

Novel tooth pathologies in Tyrannosaurus rex

Kirstin S. Brink

The morphology, frequency, and ontogeny of sociosexual agonistic behaviour in Tyrannosauridae

Caleb Brown

Update to the fossil fish type catalogue of the University of Alberta Laboratory for Vertebrate Palaeontology

John C. Bruner

A new elasmosaurid (Sauropterygia: Plesiosauria) from the non-marine Dinosaur Park Formation of southern Alberta

James A. Campbell, Mark T. Mitchell, and Jason S. Anderson

Influences of diet on the olfactory bulbs of New World leaf nosed bats

Allen V. Chochinov, Rachel A. Racicot, Simon A Darroch, and Marc Laflamme

Macroevolutionary patterns of theropod gigantism as revealed through osteohistology and growth curve reconstruction

Thomas M. Cullen, Juan I. Canale, Sebastián Apesteguía, Nathan D. Smith, and Peter J. Makovicky

Anatomy and relationships of Sinosaurus triassicus (Theropoda, Coelophysoidea) from the Lufeng Formation

(Lower Jurassic) of Yunnan, China

Philip J. Currie, Xing Lida, Wu Xiaochun, and Dong Zhiming

Is it better to be the tortoise or the hare?: Using hindlimb metrics, energetics and biomechanics to determine niche differentiation between theropod clades

T. Alexander Dececchi, Aleksandra M. Mloszewski, and Hans C.E. Larsson

Histological analysis of the hadrosaur Prosaurolophus maximus and implications for the timing of crest growth, sexual maturity, and body size

Eamon T. Drysdale, François Therrien, Darla K. Zelenitsky, and Gregory M. Erickson

Confirmation of the choristoderan neomorphic ossification and its developmental and functional origin

Thomas W. Dudgeon, Hillary C. Maddin, David C. Evans, and Jordan C. Mallon

Histopathology of a pachycephalosaur frontoparietal dome

Aaron D. Dyer, Aaron R. H. LeBlanc, and Philip J. Currie 
Stunted growth and mixed-age flocks in avimimids (Theropoda, Oviraptorosauria)

Gregory F. Funston and Philip J. Currie

Palaeoenvironmental reconstruction of a marine reptile bonebed from southwestern Saskatchewan, Canada:

Utility of sedimentology and sequence stratigraphy for reconstructing dynamic ecosystems Meagan M. Gilbert, Emily L. Bamforth, and Hallie Street

Structure and articular relationships of the partially ossified sternum in hadrosaurid dinosaurs Samantha M. Hamilton, Yan-yin Wang, Michael J. Ryan, and Corwin Sullivan

Rare, non-marine deposits during the deposition of the Bearpaw Formation: Interpreting the palaeoenvironment of the DC bonebed (Wapiti Formation) using palynology and palaeobotany.

Eva B. Koppelhus and Federico Fanti

An Isotopic Investigation of BC Pleistocene Megafauna Ecology

Cara Kubiak

Testing for ecological differences among Pleistocene and modern Yukon gray wolves (Canis lupus) using dental microwear and stable isotope analysis

Zoe Landry, Sora Kim, Hillary Maddin, and Danielle Fraser

A small theropod tooth assemblage from the St. Mary River Formation of southern Alberta: Implications for identifying isolated theropod teeth

Derek W. Larson and Kirstin S. Brink

Abandoning Tomes' 'bone of attachment': a new model for tooth attachment tissue evolution

Aaron R.H. LeBlanc

The Early Cretaceous ankylosaur Liaoningosaurus from Western Liaoning, China: Progresses and Problems

Li Xiaobo and Robert R. Reisz

Ecomorphology of flight in the avian sternum

Talia M. Lowi-Merri, Roger B.J. Benson, Santiago Claramunt, and David C. Evans

The early history of dinosaur hunting in Canada (1874-1889)

Jordan C. Mallon, Brigid E. Christison, and Darren H. Tanke

Geometric morphometric analysis of the pedal claw of Confuciusornis sanctus and its implications for diet and behaviour

Annie P. McIntosh

When amber and dinosaurs meet: Amber from dinosaur bonebeds, and dinosaur remains preserved in amber

Ryan C. McKellar, Lida Xing, and Pierre F.D. Cockx

Oldest known freshwater paracanthopterygian fish (Teleostei: Acanthomorpha) from the Maastrichtian of Alberta, Canada

Alison M. Murray, Donald B. Brinkman, Michael G. Newbrey, and Andrew G. Neuman

A brief history of Grande Prairie area palaeontology

Katalin M. Ormay, Robert N. Hunt, and Sheldon A. Graber

Discrete variation in maxillae of eudromaeosaur dinosaurs and its relation to trends in snout morphology

Mark J. Powers and Philip J. Currie 
Faunal composition and turnover during the late Pleistocene of Medicine Hat, Alberta

Ashley R. Reynolds and Kevin L. Seymour

Revisiting the evolution of maniraptoran pelvic musculature

Matthew M. Rhodes and Philip J. Currie

Embryonic and hatchling ankylosaurs from the Campanian of Bayan Mandahu (Inner Mongolia, People's

Republic of China) and Hermiin Tsav (Mongolia)

Robin L. Sissons, Philip J. Currie, Michael E. Burns, Victoria M. Arbour, Yuong-Nam Lee, and Dong Zhiming

Systematics of tethysaurine mosasauroids

Erin G. St Jean and Michael W. Caldwell

Tracking dinosaurs: Using modern technology to engage with prehistory

Yukiko Stranger-Galey, Richard McCrea, and Lisa Buckley

A young juvenile elasmosaur skull from the Upper Cretaceous Bearpaw Formation of Saskatchewan

Hallie P. Street, Michelle M.C. Mekarski, Emily L. Bamforth, and Hans C. Larsson

A new species of plioplatecarpine mosasaur (Squamata: Mosasauridae) from the Late Cretaceous of Morocco, with a re-evaluation of the problematic taxon 'Platecarpus' ptychodon

Catherine R.C. Strong and Michael W. Caldwell

Cranial ontogeny of Thamnophis radix (Serpentes: Colubroidea) provides novel insights into snake skull evolution

Catherine R.C. Strong, Tiago R. Simões, Michael W. Caldwell, and Michael R. Doschak

A juvenile lambeosaurine dinosaur from the Upper Cretaceous Wapiti Formation of northern Alberta

Corwin Sullivan, Nicolás Campione, Phil Bell, Robin Sissons, Federico Fanti, Matthew Vavrek, and Derek Larson

Sourcing and radiocarbon dating mammoths (Mammuthus sp.) of British Columbia Laura Termes

Vertebrate Remains from the Late Cretaceous Brazeau Formation of the Alberta Foothills Aaron J. van der Reest, S. Andrew DuFrane, Alberto V. Reyes, and Philip J. Currie

FreqMorph: model of morphological evolution with empirical character state frequencies

Oksana V. Vernygora

Ontogenetic change in humeri of the ceratopsian dinosaur Pachyrhinosaurus lakustai

Rebekah M. Vice and Corwin Sullivan

New juvenile specimens of Gorgosaurus libratus provide insight into the cranial ontogeny of albertosaurine tyrannosaurids

Jared T. Voris, Darla K. Zelenitsky, François Therrien, Lawrence M. Witmer, Ryan C. Ridgley, and Philip J. Currie

Osteological correlates indicate the existence of uncinate processes in fossil archosaurs

Yan-yin Wang, Corwin Sullivan, and Aaron R.H. LeBlanc

Ontogenetic niche shifts in megaherbivorous dinosaurs of the Late Cretaceous of North America

C.A. Wyenberg-Henzler and Jordan C. Mallon 


\section{A Maastrichtian-aged leptoceratopsid from the Sustut River, northern $\mathrm{BC}$, and potential for new vertebrate fossil discoveries in the Sustut Basin}

Victoria M. Arbour', David C. Evans ${ }^{2}$, D. Jade Simon ${ }^{2,3}$, and Thomas M. Cullen ${ }^{4}$

${ }^{1}$ Department of Knowledge, Royal BC Museum, Victoria, BC, V8V 9W2, Canada; varbour@royalbcmuseum.bc.ca

${ }^{2}$ Department of Natural History, Royal Ontario Museum, 100 Queens Park, Toronto, ON, M5S 2C6, Canada

${ }^{3}$ Department of Ecology \& Evolutionary Biology, 25 Willcocks St, Toronto, ON, M5S 3B2, Canada

${ }^{4}$ Department of Geology, Field Museum of Natural History, 1400 South Lake Shore Dr, Chicago, IL, 60605, USA

A partial ornithischian dinosaur skeleton discovered near the Sustut River in 1971 has, to date, represented the only vertebrate fossil remains reported from the Sustut Basin in northern British Columbia, Canada, but the geological provenance and age of this specimen has remained unclear. We undertook an exploratory survey of the area near the confluence of Birdflat Creek and the Sustut River, the region in which the dinosaur was discovered in 1971. We discovered a fragment of the turtle Basilemys sp. at a site closely matching field notes describing the initial collection of the dinosaur; no new dinosaur bones were recovered but the preservation of the Basilemys and dinosaur fossils are similar, suggesting that the new turtle fossil derives from the same locality as the dinosaur. Palynomorphs collected from this site include the marker taxon Pseudoaquilapollenites bertillonites, found in the lower Hell Creek Formation and suggesting an age of $-67 \mathrm{Ma}$ for the Basilemys and dinosaur. To the west of this locality we discovered multiple new fossil plant sites preserving wood and the leaves of Metasequoia and angiosperms.

The Sustut River dinosaur was initially described as an indeterminate bipedal neornithischian, perhaps resembling a thescelosaurid in overall body shape and size. Here we reinterpret the material as belonging to a leptoceratopsid ceratopsian, based on the morphology of the pedal phalanges. The Sustut River leptoceratopsid includes fragments of the left scapula and right coracoid, a complete left radius, partial left ulna, partial articulated right tibia and fibula, and articulated digits III and IV from the right pes, as well as an unprepared block removed from the posterior surface of the tibia that appears to contain four metatarsals. At $\sim 67 \mathrm{Ma}$ in age, the Sustut River leptoceratopsid is younger than the known stratigraphic range for Montanoceratops (71.5-68.5 Ma) and either overlaps with or is slightly older than other known Leptoceratops (66.7-66.4 Ma). Proportions of the ulna and pedal phalanges distinguish the Sustut River leptoceratopsid from Leptoceratops. Although we did not find additional leptoceratopsid material during our 2017 field expedition, the presence of additional vertebrate fossils in a heavily vegetated region of the Sustut Basin suggests that continued prospecting in the northern, more alpine regions of the basin has great potential to yield new fossil discoveries. 


\section{The Triceratops 'Baby Book': An update on juvenile ceratopsians from the Frenchman Formation of Saskatchewan, Canada}

\section{Emily L. Bamforth}

Royal Saskatchewan Museum, T. rex Discovery Centre, Eastend, SK, S0N 0T0, Canada; emily.bamforth@gov.sk.ca

The large ceratopsian Triceratops is the most common dinosaur taxon found in the latest Maastrichtian of central North America (Goodwin et al. 2006). In the upper Hell Creek Formation of Montana, coeval with the Frenchman Formation of southern Saskatchewan, Triceratops account for $70 \%$ of all dinosaur material recovered (Horner et al. 2011). While the vast majority of known specimens are adults or subadults (Horner et al. 2011), an ontogenetic growth series of this animal has been reported from the Hell Creek Formation (Horner and Goodwin 2006; Goodwin et al. 2006). The ontogeny of Canadian Triceratops specimens is poorly known however, as only two juvenile specimens have been formally described (see Tokaryk 1997). Herein is provided an update on the presence of juvenile ceratopsians (cf. Triceratops) in the Frenchman Formation of Saskatchewan, as well as an updated growth series based on supraorbital horncores. With the inclusion of the specimens reported here (Fig. 1), all of the growth stages proposed by Horner et al. (2006) to describe the ontology of Triceratops are now reported from Canada.

The smallest horncore, P2623.1, was collected from the Frenchman River Valley by Wendy Sloboda and measures only $65 \mathrm{~mm}$. The next smallest, P2299.1, measuring $95 \mathrm{~mm}$, was collected by Frank MacDougall from Grasslands National Park, SK. Both of these specimens, originally described by Tokaryk in 1997, display the 'stubby' fore-shortened supraorbital hores that Horner et al. (2006) ascribe to the 'Baby' growth stage. To these previously described specimens, we can now add that of a small juvenile, collected from Grasslands National Park in 2017 and 2018. This right supraorbital horncore, P3228.1, is $118 \mathrm{~mm}$ in length and corresponds to the growth stage represented by MOR1199, which Horner et al. (2006) include as part of the 'Juvenile' growth stage. The orbital horn would have been relatively straight with a slight posterior curve at the distal end. In 2007, McGill University collected the complete skull of a subadult Triceratops, P2982.1, from the Frenchman River Valley near Eastend. The supraorbital horncore from this animal measures $585 \mathrm{~mm}$ and - like MOR1122, a specimen of a similar size described by Horner et al. (2006) - this horn would have pointed anteriorly. For the first time in the growth series, it is partially hollow at its proximal end, and can be ascribed to Horner et al.'s (2006) 'Subadult' growth stage. Finally, we included the right supraorbital horncore of the adult Triceratops specimen P2525.1 from the Frenchman Formation for comparison. This specimen measures $850 \mathrm{~mm}$, is hollow at its proximal end, and conforms with Horner et al.'s (2006) description of a specimen from the 'Adult' growth stage. Taken together, the five specimens demonstrate the Frenchman Formation of Saskatchewan contains representatives from all described growth stages of Triceratops.

\section{Literature Cited}

Goodwin, M.B., W.A. Clemens, J.R. Horner, and K. Padian, 2006. The smallest known Triceratops skull: new observations on ceratopsid cranial anatomy and ontogeny. Journal of Vertebrate Paleontology 26:103-112.

Horner, J.R. and M.B. Goodwin. 2006. Major cranial changes during Triceratops ontogeny. Proceedings of the Royal Society of London B: Biological Sciences 273(1602): 2757-2761

Horner, J.R., M.B. Goodwin and N. Myhrvold. 2011. Dinosaur census reveals abundant Tyrannosaurus and rare ontogenetic stages in the Upper Cretaceous Hell Creek Formation (Maastrichtian), Montana, USA. PloS One 6(2): e16574. Tokaryk, T.T., 1997. First evidence of juvenile ceratopsians (Reptilia: Ornithischia) from the Frenchman Formation (late Maastrichtian) of Saskatchewan. Canadian Journal of Earth Sciences, 34:1401-1404. 


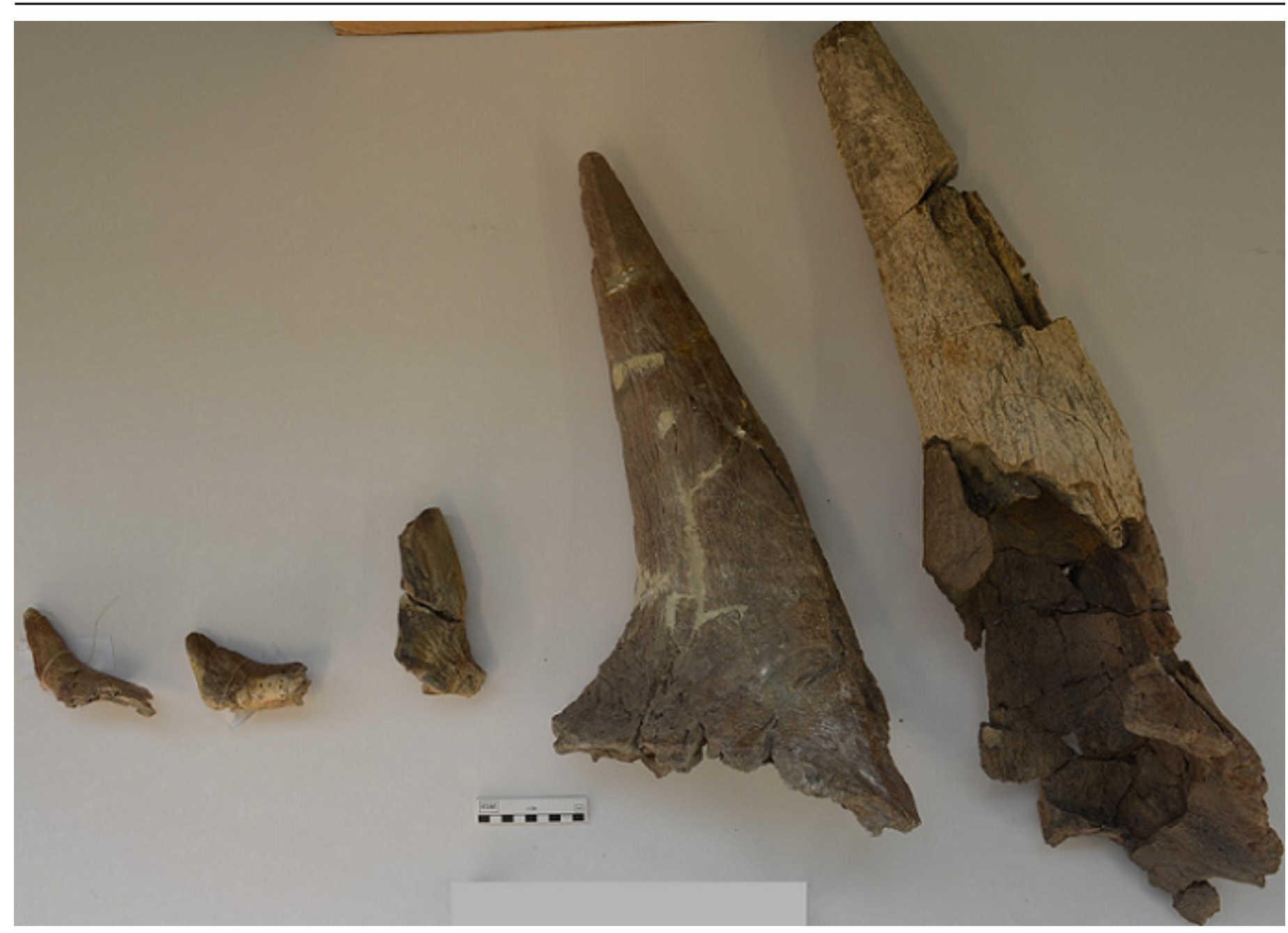

Figure 1. A growth series of right supraorbital horncores from Triceratops specimens collected from Saskatchewan. Specimens, from left to right, are RSM P2623.1, RSM P2299.1, RSM P3228.1, RSM P2982.1 and RSM P2525.1. 


\section{Campanian conundrum: Large-scale spatial diversity patterns elucidate Judith River and Dinosaur Park Formation equivalents in Saskatchewan, Canada}

\section{Emily L. Bamforth ${ }^{1}$ and Meagan M. Gilbert ${ }^{2}$}

${ }^{1}$ Royal Saskatchewan Museum, T. rex Discovery Centre, Eastend, SK, S0N 0T0, Canada; emily.bamforth@gov.sk.ca

${ }^{2}$ University of Saskatchewan, Department of Geology. Saskatoon, SK, S7N 5E2, Canada; m.m.gilbert13@gmail.com

That the province of Saskatchewan contains late Campanian-aged fossil-bearing deposits coeval with those in Alberta and Montana is not new information. These Saskatchewan deposits have been documented in a number of palaeontological publications (e.g., Eberth et al. 1990; Tokaryk and Harrington 1992), and were referred to generally as the 'Judith River Formation' (JRF). However, these deposits were sometimes more similar, geologically and palaeontologically, to the Dinosaur Park Formation (DPF) of Alberta. This rendered the designation of Saskatchewan's late Campanian rocks as a northern extension of the JRF somewhat problematic. Would it be more correct to refer to the deposits are an eastern extension of the DPF? The fact that outcrops of this aged rock in Saskatchewan are sparse, discontinuous and often difficult to access further complicated the issue.

In 2018, the terrestrial-to-marginal marine late Campanian formation underlying the fully marine Bearpaw Formation in Saskatchewan was formally assigned to the DPF. Based on stratigraphy and biostratigraphy, it was suggested to be coeval with the upper DPF of Alberta (Gilbert et al. 2018). However, it was evident from this and more recent studies that the Saskatchewan DPF is unique in and of itself, containing several sedimentological anomalies that differentiate it from both the Albertan DPF and the coeval Coal Ridge and Woodhawk members of the JRF (Gilbert et al. 2019). Saskatchewan's DPF potentially contains important information about the role of paleolatitide and proximity to the paleocoastline in shaping Late Campanian paleobiodiversity patterns across western North America. Despite this, a lack of quantitative spatial comparative studies has rendered it unclear how Saskatchewan's DPF paleoecology relates to that in coeval formations external to the province.

In this study, we conducted the first large-scale spatial beta ('among-site') diversity analysis of Dinosaur Park and Judith River paleocommunities across Alberta, Saskatchewan and Montana. A total of twelve well-sampled DPF/JRF microvertebrate sites from each of the three locations were included in this preliminary study. In these occurrence-based diversity analyses, each microvertebrate assemblage represents a single paleocommunity ('point'). Non-metric multidimensional scaling was used to ordinate the points, which were then transposed onto a spatial (geographical) plane. Weighted minimum spanning networks were plotted to better identify patterns. Although paleocommunities within Saskatchewan contained many of the same taxa, intra-provincial beta diversity was high, with the Saskatchewan assemblages being more similar to the Alberta or Montana than to one another. Perhaps tellingly, the Saskatchewan site closest to the US border was the most similar to the JRF assemblages, while the site furthest to the west was most similar to the Albertan DPF assemblages. The high beta diversity amongst Saskatchewan paleocommunities may be due to the shifting paleoenvironments associated with the Western Interior Sea, as the stratigraphic record demonstrates a prevalence of estuarine environments with frequent marine inundations. Marine influence and by extension, proximity to the paleocoastline, may therefore have been a major driver of this spatial heterogeneity. Future research, including increasing the sample size, will help to elucidate why north-south and east-west spatial heterogeneity exists in the DPF and JRF.

\section{Literature Cited}

Eberth, D.A., D.R. Braman, and T.T. Tokaryk. 1990. Stratigraphy, sedimentology and vertebrate paleontology of the Judith River Formation (Campanian) near Muddy Lake, west-central Saskatchewan. Bulletin of Canadian Petroleum Geology 38:387-406. 
Gilbert, M.M., E. L. Bamforth, L.A. Buatois, and R.W. Renaut. 2018. Paleoecology and sedimentology of a vertebrate microfossil assemblage from the easternmost Dinosaur Park Formation (Upper Campanian) Saskatchewan, Canada: Reconstructing diversity in a coastal ecosystem. Palaeogeography Palaeoclimatology Palaeoecology 495:227-244.

Gilbert, M.M., L.A. Buatois, and R.W. Renaut. 2019. Ichnology and depositional environments of the Upper Cretaceous Dinosaur Park-Bearpaw formation transition in the Cypress Hills region of Southwestern Saskatchewan, Canada. Cretaceous Research, 98:189-210.

Tokaryk, T.T. and C.R. Harington. 1992. Baptornis sp.(Aves: Hesperornithiformes) from the Judith River Formation (Campanian) of Saskatchewan, Canada. Journal of Paleontology 668:1010-1012.

\section{Latest Cretaceous climate proxies using carbon and hydrogen isotopes from plant wax-lipids}

\section{Robert D. Bourque, Peter Douglas, and Hans C.E. Larsson}

McGill University, Montreal, Quebec, H3A 0E8, Canada; robert.bourque@mail.mcgill.ca; peter.douglas@mcgill.ca; hans.ce.larsson@mcgill.ca

The research project focuses on analyzing the hydrogen and carbon isotopes of plant wax-lipids from several sites in southern Saskatchewan, Canada, to gain a better understanding of hydrological and carbon-cycle changes across the Cretaceous-Paleogene (K-Pg) boundary. The K-Pg boundary is associated with a large bolide impact that likely caused a mass extinction event. However, competing theories have suggested that the Deccan traps flood basalts that were active around the time of the impact may also have played a major role in the extinction event before the impact occurred. Three sites in Saskatchewan were selected for sample collection owing to the excellent preservation of the K-Pg boundary and excellent stratigraphy on either side of the boundary for observing relatively long-term changes encompassing the global extinction event. $\mathrm{N}$-alkyl lipids were extracted from the sediments collected by removing polar molecules from solution and then run through an isotope ratio mass spectrometer to measure the stable isotopic ratios of carbon and hydrogen which reflect changes in the carbon and water cycles respectively. Additionally, bulk carbon and total organic carbon measurements were taken over the same interval to compare with the results of past studies. Our results provide a unique opportunity to observe changes in both the carbon-cycle and hydrological cycle across K-Pg boundary. We also evaluate change through sections before and after the event to evaluate the long-term effects of the Deccan traps on the global carbon cycles, allowing us to infer what effects the Deccan traps had on a global scale, when they were most influential. Carbon results show a continuous enrichment in $\delta 13 \mathrm{C}$ in atmospheric $\mathrm{CO}_{2}$ spanning across the boundary, which could potentially be attributed to the Deccan Traps volcanism or an increased rate in organic carbon burial. While the volcanism model does line up with some studies, it is still a heavily debated topic with a variety of studies providing contradicting evidence, and a far larger volume of $\mathrm{CO}_{2}$ would need to be released from the Deccan Traps to justify a 2 ppm shift than what seems likely based on measurements of modern volcanism. The hydrogen isotopes between the two sites examined show somewhat different trends that suggest they are more heavily affected by localized conditions, however there are repeating patterns consistent between the two sites that suggest Milankovitch cycles may be observed over the sedimentary depositional sequences. Additionally, changes observed in both isotopic records do not show a strong deviation around the boundary, which may suggest that these systems recovered in a relatively quick geologic time scale. 


\section{Novel tooth pathologies in Tyrannosaurus rex}

\section{Kirstin S. Brink}

Department of Oral Health Sciences, Faculty of Dentistry, University of British Columbia, 2350 Health Sciences

Mall, Vancouver, BC, V6T 1Z3, Canada; kirstin.brink@gmail.com

Dental pathologies in theropod dinosaurs are relatively common. Most occurrences such as split, multiple, or dysmorphic carinae, where the overall shape of the tooth is normal but the carinae are abnormal, appear to be caused by genetic factors. However, teeth associated with the skull of the Tyrannosaurus rex SUE (Field Museum of Natural History PR2081) show abnormalities in overall tooth shape, including malformation and gemination or fusion (double teeth). Tooth gemination occurs in humans because of the incomplete splitting of one follicle while fusion occurs with the joining of two follicles early in development. The cause of the splitting or fusion is unknown, as this occurs in utero and is difficult to study. As theropod dinosaurs are polyphyodont, the development of a geminated tooth can occur postnatally, offering the rare opportunity to determine how these pathologies form.

FMNH PR5081 was previously diagnosed with an oral infection common to birds, trichomonosis. To determine if the pathologic teeth in FMNH PR5081 were caused by infection, two steps were taken. First, the skull was segmented using published CT scans in order to determine if the pathologic teeth originated from an area that could have been affected by infection. Second, a survey of the literature was undertaken to determine the causes of tooth abnormalities during development. Results suggest that the teeth originated from several empty or near-empty alveoli from the back of the left maxilla, dorsal to the area of Trichomonas infection in the mandible. Although the skull is slightly crushed, there is no evidence of bone lesions or other disruptions near the teeth. Therefore, it is possible that the infection spread to the soft tissues of the upper jaw where the geminated teeth originated. This would have disrupted the dental follicle such that tooth development was able to proceed, creating the pathologic teeth. A survey of the literature shows very few studies examining tooth defects through infection and disease in polyphyodont animals, as most reports focus on diagnoses and treatments of the soft tissue. Future work will require the documentation of skeletal and dental effects of infection and disease in polyphyodont animals in order to confirm that the pathology seen in T. rex could indeed have been caused by an infection. This study is an example of how non-traditional model organisms, such as dinosaurs, can offer new perspectives to understand dental pathologies such as tooth gemination in living animals. 


\section{The morphology, frequency, and ontogeny of sociosexual agonistic behaviour in Tyrannosauridae}

\section{Caleb Brown}

Royal Tyrrell Museum of Palaeontology, Drumheller, AB, Canada

Intraspecific, sociosexual interactions, often in the form of male-male intrasexual aggression, are key to understanding the behavioral ecology, sexual selection, and reproductive systems of animals. In modern species, these behaviours can be studied through direct observation, or inferred from frequency of wounds/scars within sample populations/species. These data however, are rarely available for extinct taxa.

Healed/partly healed scars on cranial bones, interpreted as intraspecific bite marks, have been noted in several species of tyrannosaur, presenting a unique opportunity to study intraspecific aggression in an extinct taxon. While previous research on tyrannosaur face biting has largely concentrated on small samples of articulated/associated skulls, or single specimens, the current study also makes use of isolated specimens, vastly increasing both the overall sample size and the size/age range (specifically small/young individuals). This sample allows for quantifying patterns of occurrence (i.e., bone, position, orientation), frequency, and ontogeny of intraspecific agonistic behavior.

More than 35 articulated/associated skulls (complete and incomplete) and 179 isolated elements (486 elements total) were examined, and more than 282 bite scars documented across Gorgosaurus, Albertosaurus and Daspletosaurus. Bite scars are most commonly seen on the dentary $(47 / 92$, freq. $=51 \%)$ and maxilla $(34 / 81$, freq. $=41 \%)$, and to a lesser extent the angular $(22 \%)$, surangular $(18 \%)$, jugal $(9 \%)$, nasal $(7 \%)$, lacrymal $(6 \%)$, postorbital (6\%), and premaxilla (5\%). A distinct and consistent pattern is observed on the position and orientation of the bite scars. On the maxilla bite scars are expressed as circular/oval punctures dorsally, and highly elongate, diagonal-oriented scars laterally, while this pattern inverted for the dentary.

Bite scars are completely absent on elements/skulls with tooth row lengths less than $250 \mathrm{~mm}(-45 \%$ max length). Above this size threshold, bites are frequent, but while the number of scars per element increase with body size, the frequency of elements with bite scars is stable (freq. $=-50-60 \%$ ). Comparison of mean tooth spacing between serial scars on the element, and serial teeth of the element, shows a significant and isometric correlation (i.e., bittenee and biter are of similar size) suggesting only animals of comparable size engaged in this behaviour. Bite mark data from several extant taxa, including Alligator and Australian water dragons (Physignathus), show a strong correlation between the onset of bite marks and sexual maturity, suggesting this may be the same in tyrannosaurids.

The lack of bite marks in approximately half of the sample (even at large body size) suggests that some individuals never engaged in this behaviour, and may superficially resemble a sexual distinction. To put the tyrannosaur dataset in context, a dataset of sex specific bite mark/scar frequency in extant taxa was assembled (114 datasets, 81 species). Of these, 103 (90\%) show a higher frequency of scars in males than females, while five $(4 \%)$ show equal frequencies between the sexes. Despite this dominance of bite scars in males, in only 10 datasets $(9 \%)$ are the scars exclusive to males, with no scars in females, suggesting caution in using bite scars to inform on sex in Tyrannosauridae. 


\section{Update to the fossil fish type catalogue of the University of Alberta Laboratory for Vertebrate Palaeontology}

\section{John C. Bruner}

jbruner@ualberta.ca

The first list (Bruner, 2019) ever compiled of the fossil fish types deposited in the collections of the University of Alberta Laboratory for Vertebrate Paleontology (UALVP) found 88 fish holotypes, 966 fish paratypes, 55 casts of fish holotypes and 20 casts of fish paratypes from other museums. Thirteen fish 'holotypes' and 156 fish 'paratypes' languishing in unpublished Ph.D. theses and M.Sc. theses are also included in the list as they are labeled in the collections as 'types' on the museum labels and in the computer catalogue. Also, this type catalogue lists specimens incorrectly cited as holotypes and paratypes in the scientific literature. Two weeks after the publication of the fish type catalogue, it was discovered someone with access to the UALVP Mimsy computer catalogue had overwritten over 400 entries for two fields 'Class' and 'Type status' for each catalogue number. For the 'Class' field, the previous entry was erased and 'Mammalia' was inserted. For the 'Type status,' a blank entry was inserted over any entries for Holotype and Paratype. Also, an unknown number of Mimsy catalogue numbers were completely erased and tetrapods were catalogued for these already used catalogue numbers. This unfortunate overwriting of records and double use of numbers resulted in the fish types in these 400 plus catalogue entries being missed in computer searches of the catalogue. Twenty-two published paratypes, 6 holotypes and 32 paratypes in a Master of Science thesis were missed. Also, a new description of a Cretaceous sturgeon, Anchiacipenser acanthaspis Sato, Murray, Vernygora and Currie, 2018 has been published. The UALVP fish collection new totals are: 89 fish holotypes, 988 fish paratypes; 55 casts of fish holotypes and 20 casts of fish paratypes from other museums; and, 19 fish 'holotypes' and 188 fish 'paratypes' from unpublished Ph.D. theses and M.Sc. theses.

\section{Literature Cited}

Bruner, J.C. 2019. Type Specimens of Fossil Fishes: Catalogue of the University of Alberta Laboratory for Vertebrate Paleontology. CRC Press, Boca Raton, Florida, 166 pp. ISBN 9780429398582 CAT\# KE69888 Published January 10, 2019. Hardback $\$ 69.95$; ebook $\$ 62.96$; ebook rental from $\$ 34.98$

Sato, H., A.M. Murray, O. Vernygora, and P.J. Currie. 2018. A rare, articulated sturgeon (Chondrostei: Acipenseriformes) from the Upper Cretaceous of Dinosaur Provincial Park, Alberta, Canada. Journal of Vertebrate Paleontology DOI: 10.1080/02724634.2018.1488137. 


\title{
A new elasmosaurid (Sauropterygia: Plesiosauria) from the non-marine Dinosaur Park Formation of southern Alberta
}

\author{
James A. Campbell ${ }^{1}$, Mark T. Mitchell ${ }^{2}$, and Jason S. Anderson ${ }^{3}$
}

\author{
${ }^{1}$ Department of Biological Sciences, University of Calgary, 2500 University Drive NW, Calgary, AB, T2N 1N4, Canada; \\ james.campbell2@ucalgary.ca \\ ${ }^{2}$ Royal Tyrrell Museum of Palaeontology, Box 7500, Drumheller, AB, T0J 0Y0, Canada; mark.mitchell@gov.ab.ca \\ ${ }^{3}$ Department of Comparative Biology and Experimental Medicine, University of Calgary, 3330 Hospital Drive NW, \\ Calgary, AB, T2N 4N1, Canada; janders@ucalgary.ca
}

Plesiosaurs are an enigmatic group of aquatic reptiles that lived from Late Triassic to Late Cretaceous time. They are known primarily from marine deposits but also occur sparingly from non-marine units such as the fluvial and estuarine sediments of the Upper Cretaceous (Campanian) Dinosaur Park Formation (DPF) of southern Alberta. These sediments were deposited on the eastern coastal plain of Laramidia, which drained into the Western Interior Seaway to the east. The DPF has yielded a stratigraphically-extensive collection of elasmosaurid remains for over a century, but this assemblage has received relatively little attention due to the fragmentary and non-diagnostic nature of most of these specimens.

This study reports on an elasmosaurid partial skeleton collected from estuarine sediments of the Lethbridge Coal Zone in the upper DPF of southeastern Alberta. This specimen consists of the trunk region, the base of the neck, anterior half of the tail, and a partial forelimb, and represents the most complete plesiosaur specimen yet collected from this formation. This specimen has a unique combination of features that support its referral to a new genus and species. These features include: a ventral midline notch spanning the posterior cervical to anterior dorsal vertebral series; the presence of three pectoral, 20 dorsal, and five sacral vertebrae; a boomerang-shaped clavicular arch with a pointed anterior process, distinct ventral keel, and an embayment on each side of the posterior margin; and a pubis with a pronounced embayment on the anterolateral margin. The latter feature is also present in other elasmosaurid specimens from more upland, fluvial sediments of the DPF, and our referral of these specimens to this new taxon effectively expands its geographic range into the river systems of this formation.

Although this partial skeleton is incomplete, and neck length is highly variable among elasmosaurids, this individual is estimated to have had an original body length of between four and five metres. This individual is relatively small amongst elasmosaurids considering its presumed near-adult status, supported by the presence of a closed neurocentral suture in one-third of the vertebrae, complete coossification of the clavicles and interclavicle into a single unit, and moderately well-developed degree of development of external features (e.g., a humerus with well-developed epipodial facets and a moderate degree of separation between the capitulum and tuberosity). The diminutive size of this new taxon, when compared with most other marine elasmosaurids (e.g., Albertonectes, Elasmosaurus, Styxosaurus, Terminonatator), suggests that DPF elasmosaurids may have had greater constraints on body size than those inhabiting deeper-water settings. This new taxon may represent an example of niche partitioning within a predominantly marine group of extinct tetrapods. 


\title{
Influences of diet on the olfactory bulbs of New World leaf nosed bats
}

\author{
Allen V. Chochinov ${ }^{1}$, Rachel A. Racicot ${ }^{2}$, Simon A Darroch ${ }^{3}$, and \\ Marc Laflamme ${ }^{4}$ \\ ${ }^{1} 18$ Doddington Dr, Toronto, ON, M8Y1S4, Canada; allenvikram.chochinov@mail.utoronto.ca, \\ 2925 N. Mills Avenue, Claremont, CA, 91711, USA; rachel.racicot@gmail.com \\ ${ }^{3} 5726$ Stevenson Center, Nashville, TN, 37240, USA; simon.a.darroch@vanderbilt.edu, \\ ${ }^{4} 3359$ Mississauga Road, Mississauga, ON, L5L 1C6, Canada; marc.laflamme@utoronto.ca,
}

The most diverse family of bats are the Phyllostomidae (New World leaf nosed bats) with members practicing a wide variety of diets including insectivory, frugivory, nectarivory, and hematophagy. This project examines the variations in the size and shape of the phyllostomid olfactory bulbs through a comparative analysis of herbivorous and nectivorous species with those practicing insectivorous diets. Through a comparison of the relative volume and structure of the olfactory bulbs in phyllostomids we will better understand how different diets can influence the evolution of the brain. The skulls of 14 species were chosen from all 12 subfamilies of Phyllostomidae, as well as three species from the families Mormoopidae and Pteropodidae to act as outgroups. The structure and size of the brain was quantified through the production of digital endocasts using the CT data. Accurate linear and volumetric measurements of the olfactory bulbs and brain can be gathered from these models for comparison between the selected species. Due to the importance of olfaction in the behavior of nectivorous and frugivores bats, we expect the olfactory bulbs of these species to be larger when compared to insectivorous phyllostomids. These methods can later be applied to fossil bats, as the construction of digital endocasts is often used to accurately analyze the brain morphology of prehistoric animals.

\section{Macroevolutionary patterns of theropod gigantism as revealed through osteohistology and growth curve reconstruction}

\author{
Thomas M. Cullen ${ }^{1}$, Juan I. Canale², Sebastián Apesteguía ${ }^{3}$, Nathan D. \\ Smith $^{4}$, and Peter J. Makovicky ${ }^{1}$
}

${ }^{1}$ Integrative Research Center, Field Museum of Natural History, 1400 S Lake Shore Dr., Chicago, IL, 60605, USA; tcullen@fieldmuseum.org,pmakovicky@fieldmuseum.org

2 Área Laboratorio e Investigación, Museo Municipal “Ernesto Bachmann”, Villa El Chocón, Neuquén, Argentina; juanignaciocanale@yahoo.com.ar

${ }_{3}^{3}$ Área de Paleontología, Fundación de Historia Natural Félix de Azara, CEBBAD, Universidad Maimónides, Hidalgo 775, 1405 Ciudad Autónoma de Buenos Aires, Argentina; sebapesteguia@gmail.com

${ }^{4}$ Dinosaur Institute, Natural History Museum of Los Angeles County, 900 Exposition Blvd., Los Angeles, CA, 90007, USA; nsmith@nhm.org

Many theropod clades contain extremely large-bodied, or gigantic, representatives, and the repeated but independent evolution of gigantism has been a topic of longstanding interest. Data derived from bone histology combined with methods for growth reconstruction have played a key role in investigations into this issue, and 
several previous studies have used histological data to suggest that multiple theropod taxa achieved large body size through similarly drastic increases in their growth rates when compared to smaller relatives. Despite these insights, concerns remain with respect to the source of histological data used for these reconstructions, the degree of variation present in the proxies used for growth estimation, and the ubiquity of the mechanisms underlying gigantism in theropods. Disagreements exist within the literature regarding which element of the skeleton is 'best' for growth curve reconstructions, with sampling of weight-bearing versus non weight-bearing bones often, though not exclusively, being at the center of these debates. Regarding the issue of variation, potentially confounding issues remain at several scales of comparison, such as between bones of an individual (intra-skeletally), between individuals (intra-specifically), and between species (inter-specifically). Understanding the range of variation that may exist at each of these scales is critical if we are to confidentially perform reconstructions of age and growth in extinct taxa using osteohistological data.

To address these issues, we perform multi-element histological sampling of multiple individuals representing a phylogenetically broad range of theropod taxa to both expand our quantitative record of osteohistological variation among closely related taxa, and to test if particular elements consistently preserve the most complete growth record across individuals and taxa. We then perform a series of growth-curve reconstructions with these data to address the question of how theropods achieved large body size in multiple evolutionarily independent events. We find considerable variability in metrics such as growth mark count and remodelling between elements, with a relatively strong ontogenetic component to observed patterns. In skeletally mature individuals (possessing an external fundamental system, or EFS, in the periosteal margins of their bones) the fibulae can undergo substantial secondary remodelling, severely hampering age estimation and growth curve reconstruction, whereas femora continue to preserve extensive primary growth records. In skeletally-immature individuals, the fibulae have not remodelled to nearly the same extent, and thus may provide a more-complete growth record when compared to femora of the same individual due to medullary expansion in the latter. Comparisons of growth curve reconstructions (performed primarily through femoral data, but with additional curves from other elements made for comparison) between large-bodied theropods produced divergent results, with some taxa, such as tyrannosaurids, appearing to achieve large body size through a considerable increase in growth rate, and others, such as carcharodontosaurids, appearing to achieve large body size through considerable increase in growth period while maintaining a slower overall rate of growth. These differences suggest that not all theropods achieved gigantism via the same means, and that a variety of physiological strategies may have been employed depending on both environmental and phylogenetic parameters. 


\section{Anatomy and relationships of Sinosaurus triassicus (Theropoda, Coelophysoidea) from the Lufeng Formation (Lower Jurassic) of Yunnan, China}

\section{Philip J. Currie ${ }^{1}$, Xing Lida ${ }^{2}$, Wu Xiaochun ${ }^{3}$, and Dong Zhiming ${ }^{4}$}

${ }^{1}$ Department of Biological Sciences, University of Alberta, Edmonton, AB, T5G 2E9, Canada; pjcurrie@ualberta.ca

${ }^{2}$ China University of Geosciences, Beijing, 29 Xueyuan Road, Haidian District, Beijing 100083, China; xinglida@gmail.com

${ }^{3}$ Palaeobiology, Canadian Museum of Nature, PO Box 3443, Station D, Ottawa, ON, K1P 6P4, Canada; xcwu@nature.ca

${ }^{4}$ Institute of Vertebrate Paleontology and Paleoanthropology, Chinese Academy of Sciences, Beijing 100044, China, dinodong@sina.com.

A specimen of a double-crested, medium-sized theropod (5.5 $\mathrm{m}$ in length) was discovered in the Lower Jurassic Lufeng Formation (Sinemurian-Pliensbachian) in 1987 from the Kunming region. Noting similarities to Dilophosaurus wetherilli from the United States, it was briefly described (Hu 1993) as Dilophosaurus sinensis. A second skeleton was discovered in 1994 in the neighbouring Lufeng Basin, within two kilometers of where the holotype of Sinosaurus triassicus had been collected half a century earlier (Young 1948). The holotype (especially the maxilla) was studied in detail, and there can be no doubt that the second skeleton is referable to Sinosaurus triassicus. The skeleton from the Kunming region looks different superficially, but it possibly represents the same taxon. Crest development, anatomy of the femoral trochanters, and ossification of the tibiotarsus show notable differences between the two specimens. However, these same characters have been previously described in other coelophysoids as possible sexual differences. Given that the two skeletons were recovered from the same stratigraphic level (Zhangjiawa Member of the Lower Lufeng Formation) and were separated by only $80 \mathrm{~km}$, it is most parsimonious to conclude that the specimens support the suggestion that there was strong sexual dimorphism in all coelophysoids. A phylogenetic analysis suggests that Sinosaurus triassicus is a coelophysoid related to Dilophosaurus wetherilli and coelophysids, which has interesting paleobiogeographic implications. The identifications of additional specimens recovered from the Lufeng Formation in recent years - including the holotype of Shuangbaisaurus anlongbaoensis Wang, you, Pan and Wang, 2017 - are discussed. It is concluded that all fall within the range of morphological variability represented by the Kunming and Lufeng skeletons.

\section{Literature Cited}

Hu S.-J. 1993. A short report on the occurrence of Dilophosaurus from Jinning County, Yunnan Province. Vertebrata PalAsiatica 31:65-69.

Wang G.F., H.L. You, S.G. Pan, and T. Wang. 2017. A new crested theropod dinosaur from the Early Jurassic of Yunnan Province, China. Vertebrata PalAsiatica 55: 177-186.

Young, C.C. 1948. On two new saurischians from Lufeng, Yunnan, China. Geological Society of China, Bulletin 28:75-90. 


\title{
Is it better to be the tortoise or the hare?: Using hindlimb metrics, energetics and biomechanics to determine niche differentiation between theropod clades
}

\section{T. Alexander Dececchi ${ }^{1}$, Aleksandra M. Mloszewski², and Hans C.E. Larsson ${ }^{3}$}

\author{
${ }^{1}$ Department of Biology, University of Pittsburgh Johnstown, 450 Schoolhouse Road, Johnstown, PN, USA, 15904; \\ tadececchi@pitt.edu \\ ${ }^{2} 61$ Shaw Street, Kingston, ON, K7K 4Y5, Canada; aleksmlo@gmail.com \\ ${ }^{3}$ Redpath Museum, McGill University, Montreal, QC, H3A 2K6, Canada; hans.ce.larsson@mcgill.ca
}

Non-avian theropod dinosaurs were the dominant terrestrial carnivores during much of the Mesozoic. Across this diversity we see multiple anatomical specializations towards being efficient hunters. While much work has been done to examine the upper limits of energy intensive high speed chase related behaviours (running speed, turning radii), the fact is that these behaviours likely represented only a small portion of their total daily hunting strategy or energy budget. Previous research on extant systems has shown that there are metabolic limits for terrestrial hunting animals. Beyond this, modern pursuit hunters show that the higher speed - but still well below the organism's top speed - portion of the hunt is often a small fraction of the total pursuit. In addition, the speed of the chase is set more by the prey than the top speed of the hunter, and recent work has found behaviour measures are utilized in slower hunters, permitting them to subdue faster prey items. This suggests that instead of selecting for higher speed function, perhaps hindlimb features such as the elongated distal limbs of some coelurosaurs (tyrannosauroids, compsognathids) were influenced by factors involved in longer search times and pursuit efficiency. Here we combine traditional limb metrics (distal limb scores, total limb length) for a sample of 90 specimens of non-avian and early avian theropods with estimates of running speed and cost of transport. Running speed was estimated using several methods such as Froud number or stride length and compared this to the maximum possible speed based on scaling laws from modern taxa. For a subset of taxa we directly evaluated savings in terms of daily energy budget per unit time or distance covered of similar sized individuals who differed in leg length, such as tyrannosaurids vs more basal large theropods. By combining these analyses we are able to determine which factor, top speed or energetic efficiency, most parsimoniously explained differences in relative limb proportions. We find that, similar to mammals, selection for higher speed is not a constant pressure across size classes. Amongst the smaller theropods such as compsognathids or microraptorines, calculated top speeds were well below the theoretical maximum with large differences between taxa based on total limb lengths. This agrees with the idea that these taxa, beyond being predators, were often prey themselves so should maximize their ability to escape even if it was not energetically efficient. In contrast the mid to large size theropods greater than $500 \mathrm{~kg}$ showed calculated top speeds well above the theoretical maximum suggested that they have "maxed out" speed potential. In contrast the energy savings from hindlimb elongation can be substantial, representing greater than $10 \%$ of the basal daily energy expenditure. This pattern holds in subadult individuals, which have been previously assumed to have been the more active hunters. We suggest that this reduction in the influence of top speed on larger theropod hunters is partially due to prey pursuit and ecological differences between tyrannosaurids and more basal theropods. Tyrannosaurids perhaps acted more like modern canids with longer pursuits or even following migrating herds of prey, necessitating the selection of hindlimbs that maximize energy efficiency in walking and slow running context. 


\title{
Histological analysis of the hadrosaur Prosaurolophus maximus and implications for the timing of crest growth, sexual maturity, and body size
}

\author{
Eamon T. Drysdale ${ }^{1}$, François Therrien², Darla K. Zelenitsky ${ }^{3}$, and \\ Gregory M. Erickson ${ }^{4}$
}

\footnotetext{
${ }^{1}$ Department of Geoscience, University of Calgary, Earth Science Building, 2500 University Drive NW, Calgary, AB, T2N 1N4, Canada; eamon.drysdale@ucalgary.ca

${ }^{2}$ Royal Tyrrell Museum of Palaeontology, PO Box 7500, Drumheller, AB, T0J 0Y0, Canada; francois.therrien@gov.ab.ca

${ }^{3}$ Department of Geoscience, University of Calgary, Earth Science Building, 2500 University Drive NW, Calgary, AB, T2N 1N4, Canada; dkzeleni@ucalgary.ca

${ }^{4}$ Department of Biological Sciences, Florida State University, King Life Sciences Building, 319 Stadium Drive, Tallahassee, FL, 32304, USA; gerickson@bio.fsu.edu
}

Hadrosaurs are known for their elaborate cranial ornamentation that often undergoes drastic changes through ontogeny. Ontogenetic acquisition of the crest has led to the current hypothesis that this feature was used for sexual display. Development of a sexual display feature should correlate with sexual maturity, which is inferred to coincide with the initial decrease in species growth rate documented via histological studies. However, the biological timing of crest development in hadrosaur species is poorly understood. An ontogenetic series for the saurolophine hadrosaur Prosaurolophus maximus, which includes several specimens with associated cranial and postcranial material, provides an ideal case study to document the correlation between crest morphology, biological age, and sexual maturity in a hadrosaur. Histological thin sections of the tibia of four specimens of $P$. maximus curated at the Royal Tyrrell Museum of Palaeontology (TMP), including three juveniles (TMP 1983.64.3, TMP 1998.50.1, and TMP 2016.37.1) and one large specimen (TMP 1984.1.1), were studied here to determine how individual crest morphology relates to biological age. Ages were estimated by counting growth marks in thin section preserved in the tibiae, and the number of missing growth marks due to remodelling or medullary expansion was estimated using section stacking. Our results show that the crest of $P$. maximus is poorly developed at age three, has taken on the diagnostic shape of the taxon at the age of four although lacks the robustness and rugosity observed in larger specimens, and has reached full adult morphology no earlier than by the age of six. If sexual maturity coincided with development of adult crest morphology in P. maximus, then it likely occurred between the ages of four and six, which differs from sexual maturity estimates for other hadrosaurs (e.g., between two and three years of age in Maiasaura peeblesorum and Hypacrosaurus altispinus). Additionally, the largest P. maximus specimen studied here, TMP 1984.1.1, lacks an external fundamental system, the histological marker of skeletal maturity, indicating that the individual was still growing at the time of death. Comparison with other large specimens of $P$. maximus suggests the species may have reached a larger body size than represented by known specimens, making it one of the earliest large-bodied hadrosaur species known from North America. 


\title{
Confirmation of the choristoderan neomorphic ossification and its developmental and functional origin
}

\author{
Thomas W. Dudgeon ${ }^{1}$, Hillary C. Maddin ${ }^{1}$, David C. Evans ${ }^{2}$, and \\ Jordan C. Mallon ${ }^{3}$
}

${ }^{1}$ Department of Earth Sciences, Carleton University, 1125 Colonel By Drive, Herzberg Laboratories, Ottawa, ON, K1S 5B6, Canada; thomasdudgeon@cmail.carleton.ca; hillarymaddin@cunet.carleton.ca

${ }^{2}$ Vertebrate Palaeontology, Royal Ontario Museum, Toronto, ON, M5S 2C6, Canada; d.evans@utoronto.ca

${ }^{3}$ Beaty Centre for Species Discovery and Paleobiology Section, Canadian Museum of Nature, P.O. Box 3443, Station D,

Ottawa, ON, K1P 6P4, Canada; jmallon@nature.ca

The choristoderan neomorphic bone (hereafter simply 'neomorph') was first identified in Champsosaurus as a small, paired, triangular element in the lateral wall of the braincase. The existence of this element was subsequently debated and some interpreted it as a simple extension of the parietal. Skepticism regarding the existence of this element is warranted because the reptile braincase is predominately chondrocranial in origin and tends to be conserved over evolutionary time. The presence of a neomorphic bone in the lateral wall of the braincase is therefore unusual.

Our research describes the cranial elements of a well-preserved specimen of Champsosaurus lindoei (CMN 8920) using computed tomography (CT) scanning. The resulting CT data were visualized and segmented to produce a three-dimensional model of the cranial elements. We confirm that the anterodorsally elongate neomorph is distinct from the surrounding ossifications. It is shown conclusively that the neomorph does not contact either the endosseous labyrinth or the cranial nerve tracts, and is separated from the endocranial cavity by the underlying prootic and opisthotic. Based on variation in the development of cranial bones in other lineages of amniotes, and the position of the neomorph relative to the surrounding elements, the neomorph is most likely dermatocranial in origin and instigated as an intramembranous ossification.

The location and size of the neomorph in Champsosaurus suggests that it played a role in supporting the temporal arches, but Coeruleodraco, an early choristodere from the Jurassic, appears to possess a neomorph that is far smaller than that seen in Champsosaurus. This suggests that the neomorph did not evolve for structural support, and may instead have arisen via non-adaptive means. In more derived choristoderes, such as Champsosaurus, the neomorph was possibly coopted to support the expanded temporal region. 


\section{Histopathology of a pachycephalosaur frontoparietal dome}

\section{Aaron D. Dyer, Aaron R. H. LeBlanc, and Philip J. Currie}

Department of Biological Sciences, University of Alberta, Edmonton, AB, T6G 2E9, Canada; adyer@ualberta.ca; arl@ualberta.ca; pjcurrie@ualberta.ca

Palaeontologists have debated the function of the pachycephalosaur frontoparietal dome, with the most prominent hypothesis being that the dome was used in intraspecific head-butting combat. Combative behaviours are likely to damage bone, making palaeopathology a useful tool in assessing the behaviours of fossil vertebrates. Previous studies utilized CT scans to identify pathologic woven bone remodeling and sclerosis (pathologic dense bone) in the lesion floors of numerous pachycephalosaur frontoparietal domes. These histopathologic features were used to diagnose such pathologies as osteomyelitis (bone infections that can form after trauma), which was used to support the hypothesis that pachycephalosaurs used their domes in intraspecific head-butting combat. However, CT scan resolution is often too coarse to identify tissue-level, pathologic features such as woven and sclerotic bone. Therefore, closer tissue-level examination is required to diagnosis osteomyelitis in pachycephalosaur domes. This study used micro-CT scans and thin-sections to test for histological evidence of bone resorption (a response to bone infection), secondary woven bone, and sclerosis in UALVP 8504 (cf. Foraminacephale), a suspected pathologic dome from the Dinosaur Park Formation, which possessed external lesions morphologically consistent with previously diagnosed osteomyelitic specimens.

Micro-CT scans produced insufficient resolution for histological analysis, possibly due to the state of preservation of UALVP 8504. Thin-sections of UALVP 8504 revealed Howship's lacunae (a histologic feature of bone resorption) along the floors of its lesions, confirming a pathologic origin. However, secondary woven bone and sclerosis were not identified in thin-sections, falsifying the diagnosis of osteomyelitis. However, the vascularized region (Zone II) of UALVP 8504 exhibits massive bilateral bone remodeling structures. Normally, this region of the dome is devoid of major remodelling. Bone remodeling frequently forms to repair microfractures and/or fatigue fractures. The remodeling structures in UALVP 8504 are oriented in the direction of strain that would form from head-butting, and where traumatic microfractures would form. As the bone remodeling indicates that the dome experienced substantial trauma, it's likely that the external pathologies also have a traumatic origin, potentially ulcerative dermatitis (skin infection). The histopathology of UALVP 8504 thus provides some of the most direct evidence of head-butting combat behaviours in pachycephalosaurs. 


\section{Stunted growth and mixed-age flocks in avimimids (Theropoda, Oviraptorosauria)}

\section{Gregory F. Funston and Philip J. Currie}

Department of Biological Sciences, University of Alberta, Edmonton, AB, Canada; funston@ualberta.ca; pjcurrie@ualberta.ca

Avimimids were unusual, birdlike oviraptorosaurs from the Late Cretaceous of Asia. Initially enigmatic, new information has ameliorated the understanding of their anatomy, phylogenetic position, and behaviour. A monodominant bonebed from the Nemegt Formation of Mongolia showed that some avimimids were gregarious, but the site is unusual in the apparent absence of juveniles. Here we describe a second monodominant avimimid bonebed from the Iren Dabasu Formation of northern China. Elements recovered include a frontal, numerous vertebrae, and portions of the forelimb and hindlimbs, representing a minimum of six individuals. Histological sampling of two tibiotarsi from the bonebed reveals unexpectedly early onset of fusion and limited subsequent growth. These results suggest that fusion of compound bones—beginning as early as the first year of life—stunted adult growth, possibly in response to aerobic limitations. The bonebed assemblage therefore provides evidence of mixed-age flocking in avimimids and suggests that some of the individuals in the Nemegt Formation bonebed may have been juveniles. Limitation of body size probably facilitated mixed-age flocking by reducing ontogenetic niche shift in avimimids.

\section{Palaeoenvironmental reconstruction of a marine reptile bonebed from southwestern Saskatchewan, Canada: Utility of sedimentology and sequence stratigraphy for reconstructing dynamic ecosystems}

\section{Meagan M. Gilbert ${ }^{1}$, Emily L. Bamforth ${ }^{2}$, and Hallie Street ${ }^{2}$}

${ }^{1}$ Department of Geological Sciences, University of Saskatchewan, Saskatoon, SK, S7N 5E2, Canada; m.gilbert@usask.ca

${ }^{2}$ Royal Saskatchewan Museum, T. rex Discovery Centre, Eastend, SK, S0N 0T0, Canada; Emily.bamforth@gov.sk.ca

The Late Cretaceous of southwestern Saskatchewan was deposited during complex interplay between transgressive marine deposits advancing from the east, and terrestrial clastics sourced from the Canadian Cordillera in the west. The Dinosaur Park-Bearpaw formation transition in Saskatchewan records the last major transgression of the Western Interior Seaway (WIS) across western North America. Due to proximity of the palaeocoastline, subtle environmental changes in marginal marine settings are recorded in Saskatchewan that are absent in other parts of the basin. These deposits offer an opportunity to understand subtle environmental mechanisms influencing faunal turnovers at transitional zones.

The Western Interior Seaway inundated and bisected North America at a time of high global sea-level and active regional tectonism occurring in western North America. This warm, shallow epicontinental seaway persisted through the entirety of the Cretaceous, and supported a wide range of vertebrate and invertebrate fauna preserved in marine shale deposits throughout Saskatchewan. In southwest Saskatchewan, the Campanian to Maastrichtian Bearpaw Formation is one of these marine units, and interfingers with terrestrial clastics of the Dinosaur Park Formation at its base. Both the Dinosaur Park and Bearpaw formations are known to be fossiliferous in 
Saskatchewan, and are the focus of several ongoing studies in recent years. The Bearpaw Formation in particular has produced a number of spectacular fossil specimens, including mosasaurs, elasmosaurs, and polycotylids.

Near Herschel, Saskatchewan, a dense multitaxic marine bonebed containing a diverse assemblage of micro, macro, and ichnofossils has been discovered. Over the course of 30 years, the Royal Saskatchewan Museum has collected over 4000 specimens from this locality, including polycotylids, elasmosaurs, mosasaurs, and a diverse assemblage of bony and cartilaginous fish. Multitaxic marine bonebeds are notoriously rare in the Cretaceous of North America, making this site of particular palaeontologic interest. Integration of vertebrate palaeontology, ichnology, sedimentology, and sequence stratigraphy has determined the Herschel site was deposited during a small scale regressive-transgressive pulse of the WIS near the time of Dinosaur Park-Bearpaw formation transition. Dynamic shoreline processes resulted in formation of barrier island-lagoon systems which underwent periodic euxinia and anoxia. This highly stressful environment would have had a profound effect on the organisms living along marginal marine coastlines during this time. This study highlights the utility of integrating multiple datasets to provide significant insight into complex depositional systems throughout not only the Cretaceous, but the entirety of Earth's history.

\section{Structure and articular relationships of the partially ossified sternum in hadrosaurid dinosaurs}

\section{Samantha M. Hamilton ${ }^{1}$, Yan-yin Wang ${ }^{1}$, Michael J. Ryan², and Corwin Sullivan ${ }^{1,3}$}

${ }^{1}$ Department of Biological Sciences, University of Alberta, Edmonton, AB, T6G 2E9, Canada; smh2@ualberta.ca; yanyin@ualberta.ca; corwin1@ualberta.ca

${ }^{2}$ michaelpjryan@gmail.com

${ }^{3}$ Philip J. Currie Dinosaur Museum, Wembley, AB, T0H 3S0, Canada

The sternum in most reptiles is a largely or entirely cartilaginous skeletal element that contacts the coracoids anteriorly and articulates with several pairs of usually cartilaginous sternal ribs. Hadrosaurids and other derived iguanodontian dinosaurs are well known for their distinctive 'hatchet-shaped' sternal ossifications, which comprise a pair of flat plates with elongate posterolateral processes. In many vertebrates the sternum contributes to the ventilatory movements of the ribcage during respiration and the structural bracing function of the shoulder girdle. Published information on hadrosaur sterna is limited to brief descriptions of typically disarticulated sternal plates, due to the fact that these bones are typically poorly preserved and seem to have easily become separated and displaced postmortem following decay of the sternum's cartilaginous portion; hence, the elements are typically missing from illustrations and museum mounts of hadrosaurid skeletons.

A newly recovered partial skeleton of a lambeosaurine hadrosaur (TMP 2015.044.0036) from southern Alberta includes well-preserved, unfused sternal plates in presumed natural midline contact. A diamond-shaped gap interrupts the line of articulation between the two plates, which are also separated anteriorly and posteriorly by shallow notches edged with unfinished bone. The sternal plates resemble those of other hadrosaurids in bearing long posterolateral processes, which comprise approximately two thirds the length of each element. The angle between the posterolateral processes is variable among ornithopod taxa and is much wider in TMP2015.044.0036 than in at least some other hadrosaurids, including Edmontosaurus (Osborn 1912; PrietoMárquez 2014). 
The lateral ends of the posterolateral processes would likely have articulated with the first two or three pairs of sternal ribs, as has been suggested for other derived iguanodontians (e.g., Norman 1980). The anterior sternal ribs were presumably very short, given the small space that would have been available between the posterolateral processes and the vertebral ribs, and such reduction of the cartilaginous component of the anterior part of the ribcage would have resulted in greater rigidity in this area. By contrast, the unfinished notches between the sternal plates suggest that cartilaginous extensions of the sternum were likely present both anteriorly and posteriorly. Although the shapes of these extensions are difficult to infer, the anterior one likely formed a plate articulating with the coracoids as reconstructed for Iguanodon (Norman 1980), as the thin, lightly grooved outer margins of the ossified sternal elements themselves seem unsuitable for direct contact with the much thicker coracoids. In this reconstruction, the width of the anterior notch would approximate the distance between the coracoids, taking into account the convexity of the coracoids themselves. The posterior cartilaginous extension of the sternum may have been long, resembling the mesosternum and/ or xiphisternum in modern crocodilians and providing seemingly necessary space for attachment of the posterior pairs of sternal ribs.

The level of ossification of the sternal plates varies among ornithopods, and some taxa show indications that the coracoids would have articulated with the anterior part of the sternum. In at least one known juvenile specimen of Edmontosaurus (LACM 23504), the sternal plates are fused together and elongated in the anterior direction and appear to bear large anterolateral depressions that could have accommodated the coracoids. In the articulated Edmontosaurus AMNH 5060 the sterna are preserved well posterior to the coracoids, despite being anteriorly extended as in LACM 23504, but Osborn (1912) suggested this separation of the sterna from the coracoids was an unnatural condition caused by "insinking" of the chest region.

Iguanodon shows a different pattern of reinforcement of the anterior part of the sternum, in that an irregular, mineralized "intersternal" element is consistently found anterior to the sternal plates and between the coracoids in articulated specimens (Norman 1980). The existence of this element was interpreted by Norman (1980) as a structural response to stresses transmitted to the pectoral region by the forelimbs, and thus as an indicator of a quadrupedal gait. Following this logic, the lack of any apparent ossification between the coracoids of TMP 2015.044.0036 raises the possibility that this hadrosaurid might have been bipedal. However, other features such as the presence of hoof-like unguals and the arched configuration of the metacarpals suggest the animal was in fact habitually quadrupedal. Absence of ossification between the coracoids might then indicate that the forelimb in TMP 2015.044.0036 bore a smaller proportion of the weight of the body than in Iguanodon, or that the minimally ossified carpals in hadrosaurids acted as shock absorbers and reduced the transmission of locomotor impacts to the pectoral girdle. Testing these possibilities will require the careful construction of biomechanical models, in which the sternum will have to be incorporated as an integral component.

\section{Literature cited}

Norman, D.B. 1980. On the ornithischian dinosaur Iguanodon bernissartensis form the Lower Cretaceous of Bernissart (Belgium). Memoires de l'Institute Royale des Sciences Naturelle Belgique 178:106.

Osborn H.F. 1912. Integument of the iguanodont dinosaur Trachodon. Memoires of the American Museum of Natural History 1:33-54.

Prieto-Márquez, A. 2014. A juvenile Edmontosaurus from the late Maastrichtian (Cretaceous) of North America: Implications for ontogeny and phylogenetic inference in saurolophine dinosaurs. Cretaceous Research 50:282-303. 


\section{Rare, non-marine deposits during the deposition of the Bearpaw Formation: Interpreting the palaeoenvironment of the DC bonebed (Wapiti Formation) using palynology and palaeobotany}

\section{Eva B. Koppelhus ${ }^{1}$ and Federico Fanti ${ }^{2}$}

${ }^{1}$ Department of Biological Sciences, University of Alberta, Edmonton, AB, T6G 2E9, Canada; ebk@ualberta.ca

${ }^{2}$ Department of Biological, Geological and Environmental Sciences, University of Bologna, Italy; Federico.fanti@unibo.it

Deposits associated with the Bearpaw seaway represent a reference marine unit that accumulated -75-73 Mya along most of the Western Interior Basin of Canada and U.S.A. In Alberta, this interval also marks the top and base of the two major Campanian-Maastrichtian non-marine wedges - the Belly River and Edmonton groups respectively. As such, the marine deposits of the Bearpaw seaway represent a significant gap in the terrestrial fossil record both from a stratigraphic and geographic perspective, limiting our comprehension of taxonomic distribution, evolution, and ecology at the end of the Cretaceous.

In 2017, a beautifully preserved hadrosaur (UALVP 57103) was recovered from the DC bonebed located approximately $10 \mathrm{~km}$ to the south-east of Grande Prairie (west-central Alberta), on the north bank of the Wapiti River. Beds exposed in the area pertain to Wapiti Unit 3 (sensu Fanti and Catuneanu 2009, 2010), which reflects high accumulation in fluvial settings during the major transgression of the Bearpaw Sea.

Overall, fine-grained floodplain deposits (including bentonitic paleosols, lenticular organic-rich mudstones, coal seams, and peat horizons) characterize major exposures of this discrete stratigraphic interval (Fanti and Miyashita 2009; Fanti and Catuneanu 2010). Exposures along the north bank of the Wapiti River near the DC Bonebed consist of tabular mudstone and siltstone interbedded with channel sandstones and minor lenticular coal seams. More specifically, the DC Bonebed occurs within a single-story, laterally-isolated channel deposit. Sandstone point bars are vertically stacked, slightly asymmetric and succession-dominated, suggesting a low rate of channel migration/avulsion (Fanti et al. in prep.).

As UALVP 57103 was embedded in coarse-grained channel deposits, the sediment that surrounded the specimen did not look promising for finding any organic material. However, select areas turned out to have well preserved continental palynological assemblages with abundant spores and pollen from ferns, conifers and flowering plants. During the excavation of the articulated dinosaur, a few plant fossils were recovered. These are all compression/impression fossils and have been identified as flowering plants.

The assemblage has abundant bisaccate conifer pollen and fern spores. There are about 25 species of fern spores in the DC bonebed matrix, some of which are microspores from heterosporous aquatic ferns. In some cases, they are still encased in the microsporangia (massulae) that have very characteristic glochidia that look like anchors. There are also fragments of megaspores, and a few small megaspores of the genus Azolla distincta. Only a few other coniferous pollen species - such as Taxodiaceaepollenites hiatus are present. Most of the pollen belongs to flowering plants, but many of them are only represented with a few specimens for each species.

The identified megaspores and microspores belong to the same species and they are the most valuable for interpreting the environment because they are always found in freshwater environments. They have extant relatives and are known to grow in wet areas, and require water to be able to reproduce. However, they are not particular good for narrowing down the stratigraphic age.

Coniferous pollen may have come from short distances, although they are not useful in constraining the stratigraphic occurrence of the site as they all have long ranges. However, some of the pollen belonging to the flowering 
plants recovered from the site have short ranges and are therefore much better for making stratigraphic interpretations (Braman 2013). The assemblage from the DC bonebed belongs to the Wodehouseia gracile - Mancicorpus glaber palyno-stratigraphic biozone (Braman 2018).

New stratigraphic and chronostratigraphic data for Wapiti Unit 3 (Fanti et al. in prep.) suggest that the DC bonebed and associated vertebrate and palynological assemblages are coeval with the Bearpaw Formation of central Alberta, and more specifically to the Bearpaw Upper Tongue (Eberth and Braman 2012). In the Edmonton area, this marine interval overlies the paralic deposits of the Strathmore Member and grades into the coal-rich beds of the Drumheller Member (Horseshoe Canyon Formation; Eberth and Braman 2012). As such, the DC bonebed palynological assemblage - combined with the few paleobotanical specimens - most likely represents deposition between 73 and 73.5 My (Lerbekmo 2002; Eberth and Braman 2012) and a rare opportunity to document in detail non-marine ecosystems in a stratigraphic interval elsewhere represented by marine deposition during the latest Campanian.

The DC bonebed palaeoenvironment is interpreted to be an area with shallow freshwater pools with abundant plants growing in and around shallow, calm water areas. Because the preservation of the spores and pollen is extremely good (with no indication of decomposition or weathering), the organic material must have been buried relatively quickly.

\section{Literature Cited}

Braman, D.R. 2013. Triprojectate pollen occurrence in the Western Canada sedimentary Basin and the Group's Global relationships. Contribution Series Number 1. Pp. 1-538. Royal Tyrrell Museum of Palaeontology, Drumheller, Alberta.

Braman, D.R. 2018. Terrestrial palynostratigraphy of the Upper Cretaceous (Santonian) to lowermost Paleocene of southern Alberta, Canada. Palynology 42:102-147.

Eberth, D. and D.R. Braman. 2012. A revised stratigraphy and depositional history for the Horseshoe Canyon Formation (Upper Cretaceous), southern Alberta plains. Canadian Journal of Earth Sciences 49:1053-1086. DOI:10.1139/e2012-035.

Fanti, F. and O. Catuneanu. 2009. Stratigraphy of the Upper Cretaceous Wapiti Formation, west-central Alberta, Canada. Canadian Journal of Earth Sciences 46:263-286.

Fanti, F., and T. Miyashita. 2009. A high latitude vertebrate fossil assemblage from the Late Cretaceous of west-central Alberta, Canada: evidence for dinosaur nesting and vertebrate latitudinal gradient. Palaeogeography, Palaeoclimatology, Palaeoecology 275:37-53

Fanti, F. and O. Catuneanu. 2010. Fluvial sequence stratigraphy: the Wapiti Formation, West-Central Alberta, Canada. Journal of Sedimentary Research 80:320-338. DOI:102110/jsr.2010.033

Lerbekmo, J.F. and D.R. Braman. 2002. Magnetostratigraphic and biostratigraphic correlation of late Campanian and Maastrichtian marine and continental strata from the Red Deer Valley to Cypress Hills, Alberta, Canada. Canadian Journal of Earth Sciences 39:539-557. 


\section{An Isotopic Investigation of BC Pleistocene Megafauna Ecology}

\section{Cara Kubiak}

Department of Archaeology, Simon Fraser University, Burnaby, BC, V5A 1S6, Canada; ckubiak@sfu.ca

As a part of the BC Megafauna Project at Simon Fraser University, this research investigates the paleoecology surrounding the late Pleistocene megafauna of British Columbia. Using a biogeochemical approach, I will apply stable isotope analysis to investigate the diet and life history of Pleistocene megafauna using the bones, tusks, and teeth they have left behind. Throughout the lifetime of an animal, isotopic signatures of what it eats and the environment in which it lives are incorporated into its body, their ratios offset by the various fractionation effects of tissue synthesis and other variable physiological factors. These signatures remain in the tissues long after the animal is deceased, and can sometimes be recovered tens of thousands, or even millions of years in the future through stable isotope analysis. This technique can provide evidence of the diet and surrounding environment of the individual specimen analyzed, giving a better understanding of the range and diversity of life these animals experienced and of their roles within the broader ice-age ecosystem. The majority of extant stable isotope data for late Pleistocene taxa come from specimens from far-northern environments, leaving a geographical gap in our understanding of some ancient environments, such as those of modern-day British Columbia. This project aims to fill these gaps in our knowledge by compiling regional data for $\mathrm{BC}$ megafauna.

Newly developed approaches in compound-specific stable isotope analysis (CSIA) allow for stable isotope data to be better interpreted in terms of trophic niche and the context of the surrounding environment. CSIA works by first breaking up the sample into specific compounds (in the case of collagen, into its individual amino acids), then analyzing and comparing the isotopic signatures of these compounds. This research will apply new methods of CSIA to the analysis of British Columbia's megafauna, providing a new, higher resolution look into the paleoecosystem.

This project is currently in its early sampling stages. In order to gain the necessary breadth of sample information, this project is designed to be a collaborative effort with museums, private collectors, and other academic institutions. If you are interested in being involved or think that you may have a relevant specimen for testing, please contact me at the email above or visit the poster session for an informational pamphlet. 


\section{Testing for ecological differences among Pleistocene and modern Yukon gray wolves (Canis lupus) using dental microwear and stable isotope analysis}

\section{Zoe Landry ${ }^{1}$, Sora Kim², Hillary Maddin ${ }^{1}$, and Danielle Fraser ${ }^{3}$}

${ }^{1}$ Department of Earth Sciences, Carleton University, Ottawa, ON, K1S 5B6, Canada; zoelandry@cmail.carleton.ca; hillary.maddin@carleton.ca

2 Department of Life and Environmental Sciences, University of California, Merced, CA, USA 95343; skim380@ucmerced.edu

${ }^{3}$ Palaeobiology, Canadian Museum of Nature, PO Box 3443 Stn “D”, Ottawa, ON, K1P 6P4, Canada; dfraser@nature.ca

Gray wolves (Canis lupus) have been present in North America since the Pleistocene. The late Pleistocene and Holocene were characterized by sustained global warming and landscape-scale ecosystem changes. These natural environmental shifts, alongside increasing anthropogenic influences, drove the extinction of many species of North American megafauna $(-88 \%$ of mammals $>44 \mathrm{~kg})$. Previous studies have demonstrated that modern wolves are opportunistic feeders and this dietary flexibility may have enabled them to survive the megafauna extinction. However, in recent decades, gray wolf populations have significantly declined. Many factors such as habitat loss, excessive hunting, and climate change have contributed to a significant loss of genetic diversity and increased risk of extinction for gray wolves. Currently, there are no sufficiently long-term studies to indicate whether dietary flexibility in wolves may facilitate their adaptation to changing environmental conditions. A better understanding of their dietary flexibility may therefore offer valuable insights into their modern conservation. Past and present diets of carnivorous animals can be compared using dental microwear analysis. Quantification of the proportions of pits and scratches indicate the amount of bone and flesh, respectively, that comprise the diet. Stable isotope analysis (SIA) is also commonly used to reconstruct diets and to better understand trophic interactions. Stable isotope ratios of carbon and oxygen $\left({ }^{13} \mathrm{C} /{ }^{12} \mathrm{C}\right.$ and $\left.{ }^{18} \mathrm{O} /{ }^{16} \mathrm{O}\right)$ are recorded in the skeletal tissue of consumers and reflect the consumed food items and water, respectively. The goal of our study is therefore to test if and how diets of Yukon gray wolves have changed from the Pleistocene to the modern day using dental microwear analysis and ratios of carbon and oxygen stable isotopes from bone carbonates.

We took molds and created casts of the carnassial teeth (lower first molar) of Pleistocene and modern wolf specimens housed at the Canadian Museum of Nature (CMN). We then analyzed the casts for dental microwear using a scanning electron microscope (SEM). The number of pits and scratches were counted for each tooth using the ImageJ software package. Samples of bone powder from the mandibles and maxillae were chemically prepared using published methodologies and analyzed for $\delta^{13} \mathrm{C}$ and $\delta^{18} \mathrm{O}$ values using a Gas Bench coupled to a continuous flow isotope ratio mass spectrometer. We analyzed the data with $\mathrm{t}$-tests using the $\mathrm{R}$ software environment to test for statistically significant differences in both microwear and stable isotope ratios between the Pleistocene and modern specimens.

We found no statistically significant difference in mean scratch and pit numbers $(\mathrm{p}>0.05)$ between the Pleistocene and modern specimens. Based on these results, we conclude that gray wolves did not increase nor decrease their bone consumption, and fed primarily on flesh during both the Pleistocene and today. This suggests that Pleistocene and modern wolves share the major components of their diet and exhibit some degree of niche conservatism. Integration of forthcoming isotope data will provide a further test based on the following predictions. Given niche conservatism, we expect gray wolves to only show changes in bone $\delta^{13} \mathrm{C}$ and $\delta^{18} \mathrm{O}$ values that reflect changes in atmospheric $\mathrm{CO}_{2}$ and water sources related to known climate changes since the Pleistocene. Once controlling for the effect of atmospheric $\mathrm{CO} 2$, we predict an enrichment in $\delta^{18} \mathrm{O}$ and $\delta^{13} \mathrm{C}$ carbonate due to warmer and wetter modern Arctic climates (for example, $-2 \%$ enrichment in $13 \mathrm{C}$ for an increase of $-8^{\circ} \mathrm{C}$ ). However, if wolves did experience shifts in prey preference since the Pleistocene - from horse to caribou for 
example - we expect ${ }^{13} \mathrm{C}$-enrichment greater than predicted for climate change alone (an additional $\sim 2 \%$ enrichment when switching from horse to caribou). The addition of $\delta^{15} \mathrm{~N}$ collagen data, which reflect trophic interactions, should provide additional, more specific data on wolf diets during this interval.

Although North American gray wolves survived the end-Pleistocene extinction, our preliminary results suggest that failure to preserve the major elements of their niche (e.g., caribou herds) may result in continued population declines, especially in the face of increasing anthropogenic influences.

\section{A small theropod tooth assemblage from the St. Mary River Formation of southern Alberta: Implications for identifying isolated theropod teeth}

\section{Derek W. Larson ${ }^{1}$ and Kirstin S. Brink ${ }^{2}$}

${ }^{1}$ Philip J. Currie Dinosaur Museum, 9301-112 Ave, Side Family Place, Wembley, AB, Canada; dlarson@dinomuseum.ca

${ }^{2}$ Department of Oral Health Sciences, Faculty of Dentistry, Life Sciences Institute, University of British Columbia, Vancouver, BC, Canada; Kirstin.brink@gmail.com

The St. Mary River Formation at the Scabby Butte locality is significant in being one of three formations preserving latest Campanian to early Maastrichtian terrestrial vertebrate assemblages in Canada. Since the initial description of the assemblage, new material has been collected from the locality, and a greater understanding of the systematics of theropod teeth in North America now allow for a redescription of the material and a revision of the theropod taxa present in the assemblage. To identify the teeth, comparisons were made to other well-sampled small theropod tooth assemblages in Alberta. Linear discriminant analysis of small theropod teeth from the Horseshoe Canyon and Dinosaur Park formations show that teeth differ morphologically between the units, with varying degrees of quantitative morphological overlap, indicating that isolated teeth can be identified in some instances. Morphologic comparisons between these units with the specimens from the St. Mary River (in southern Alberta) and Wapiti (in northern Alberta) formations show notable biogeographic differences between species present. In both the troodontid and dromaeosaurine comparisons, the St. Mary Formation theropod teeth were consistent with those in the Horseshoe Canyon Formation, likely Albertavenator curriei and an unnamed dromaeosaurine. However, both saurornitholestine and avialan teeth from the St. Mary River Formation were consistent with teeth from the younger Dinosaur Park Formation rather than the Horseshoe Canyon Formation, representing Saurornitholestes rather than Atrociraptor and bird teeth not present in the Horseshoe Canyon Formation. The Wapiti Formation teeth, in contrast, were entirely consistent with the penecontemporaneous Horseshoe Canyon Formation. This suggests diachronous species turnover of small theropod dinosaurs in the latest Campanian of western North America, with some elements of more archaic assemblages persisting further south. 


\section{Abandoning Tomes' 'bone of attachment': a new model for tooth attachment tissue evolution}

\section{Aaron R.H. LeBlanc}

Department of Biological Sciences, University of Alberta, Biological Sciences Building, Edmonton, AB, T6G 2E9, Canada; arl@ualberta.ca

In the late 19th century, Charles Tomes presented a dichotomy in vertebrate dental anatomy: mammals and crocodilians have a suite of tooth attachment tissues suspending each tooth in its socket, whereas other reptiles, amphibians, and fish have teeth that are fused in place by a single 'bone of attachment'. This dichotomy has influenced our understanding of dental evolution for nearly 150 years, despite few attempts to explain how or why mammals and crocodilians have converged on a similar and apparently unique tooth attachment system. The result has been a largely implicit evolutionary scenario where an ancestral amniote lineage evolved progressively more complex attachment tissues from a single 'bone of attachment', culminating in the cementum, periodontal ligament, and alveolar bone in mammals and crocodilians. This Differentiation Hypothesis (DH) has been intensely scrutinized with the recent discovery of 'mammal-like' attachment tissues in squamates, marine reptiles, diadectids, dinosaurs, and stem mammals, suggesting that these tissues did not evolve independently in mammals and crocodilians, but are homologous across Amniota. Most importantly, researchers have now identified cementum, periodontal ligament, and alveolar bone in extant snakes, which Tomes used to originally characterize 'bone of attachment'. 'Bone of attachment' has thus become the histological equivalent of a nomen nudum in taxonomy; the original description was too vague to apply to any of the three periodontal tissues that are actually present in snakes. What remains, however, is to identify a mechanism of evolutionary change that could lead to the diversity of tooth attachment modes across Amniota and to explain why so many amniotes have teeth that are fused to the jaws despite having homologous dental tissues to those in mammals.

Here I present the Heterochrony-Mineralization Hypothesis (HMH) as an alternative to the $\mathrm{DH}$. As a synthesis of previous work on tooth development in reptiles and synapsids, I devise a novel scheme for characterizing tooth attachment that accounts for the amounts and directions of growth of cementum and alveolar bone. The HMH provides a framework for characterizing which of these tissues fuses a tooth to the jaws and models the ligamentous tooth attachment present in some amniotes as a heterochronic truncation of normal tooth development. Using this model, I highlight how most reptiles have evolved cementum-dominated ankylosis (teeth fused to the jaws), with some species retaining a gomphosis (ligamentous attachment) by truncating cementum growth. By comparison, many stem mammals possessed an alveolar bone-dominated ankylosis, whereas others truncated alveolar bone development and retained a gomphosis. These alternative patterns may thus also provide useful phylogenetic information in the future. The HMH not only reconciles differences in tooth attachment across amniotes, but also could clarify these similar aspects of dental evolution in other vertebrate groups. 


\section{The Early Cretaceous ankylosaur Liaoningosaurus from Western Liaoning, China: Progress and problems}

\section{Li Xiaobo and Robert R. Reisz}

College of Earth Sciences, Jilin University, Changchun 130061, China; and Department of Biology, University of Toronto Mississauga, ON, L5L 1C6, Canada; and Dinosaur Evolution Research Center, International Center of Future Science, Jilin University, Changchun 130012, China; lixiaobo@jlu.edu.cn

Ankylosauria is an extremely specialized group among ornithischian dinosaurs, with armor in the form of bony osteoderms. Although originating in the early Jurassic Period, Ankylosauria did not appear in eastern Asia until the Early Cretaceous (Vickaryous et al. 2004; Arbour et al. 2016). A diverse dinosaurian faunal assemblage has been discovered in Early Cretaceous strata (Jehol Biota) of Western Liaoning, and the ankylosaur Liaoningosaurus within it might be the earliest known Asian ankylosaurid genus. Liaoningosaurus is important and interesting because it possesses some unusual structures: the retention of the external mandibular fenestra, the potential presence of antorbital fenestrae (Xu et al. 2001), long and sharp points on the tooth crowns (fork-like) (Ji et al. 2016), and the potential presence of osseous ventral armor (Xu et al. 2001; Zheng 2018). Taxonomically, Liaoningosaurus had been placed in Nodosauridae (Xu et al. 2001), assigned to Ankylosauria (Vickaryous et al. 2004), and viewed as a very basal member of Ankylosauridae (Thompson et al. 2012). The holotype of Liaoningosaurus paradoxus (IVPP V12560) has been described as a juvenile ankylosaur (Xu et al. 2001), and recent histological work suggested that the specimen was less than 12 months old (Zheng 2018). Another distinct viewpoint is that it might be a fish-hunting adult and adapted to a partially aquatic lifestyle (Ji et al. 2016). Chuanqilong chaoyangensis is another ankylosaur species in the Jehol Biota, found in the Jiufotang Formation (Han et al. 2014); it is a large bodied ankylosaur and obviously an adult. Two ankylosaur bones, a scapulocoracoid and humerus, from the Jiufotang Formation have been assigned to an unknown family (Ji et al. 2014). There is a possibility that Liaoningosaurus and Chuanqilong might be the same species at different ontogenic stages (Zheng 2018). The shield like structures preserved in the IVPP V12560, originally named as the ventral pelvic shield (Xu et al. 2001), and one of the arguments for the semi-aquatic lifestyle hypothesis (Ji et al. 2016), has been brought into question and reinterpreted as a skin impression (Arbour et al. 2014). A more recent study suggested that the structure may have been formed by the ventral pelvic shield and an epidermal scale cover (Zheng 2018). Currently available information indicates that the known material belonging to Liaoningosaurus was unearthed from the Yixian Formation at four different localities and in the Jiufotang Formation at another locality, and there are at least 20 specimens stored in different institutions. However, only a small part of the collections had been described and analyzed, which made it difficult to understand the ontogeny of this ankylosaur. Recently, we studied three specimens stored in Jilin University, and found some osteological features clearly showing that they represent juvenile individuals. We plan to expand our study of Liaoningosaurus, examine all known specimens, determine their geographic and stratigraphic range, and compare the levels of ossification of various parts of the skeleton, including the osteoderm, allowing us to determine their ontogeny, potential lifestyle, and taxonomy.

\section{Literature Cited}

Arbour, V.M., M.E. Burns, P.R. Bell, and P.J. Currie. 2014. Epidermal and dermal integumentary structures of ankylosaurian dinosaurs. Journal of Morphology 275:39-50.

Arbour, V.M., and P.J. Currie. 2016. Systematics, phylogeny and palaeobiogeography of the ankylosaurid dinosaurs. Journal of Systematic Palaeontology 14:385-444.

Han, F., W. Zheng, D. Hu, X. Xu, and P.M. Barrett. 2014. A new basal ankylosaurid (Dinosauria: Ornithischia) from the Lower Cretaceous Jiufotang Formation of Liaoning Province, China. PLoS ONE 9(8): e104551.

Ji, Q., X. Wu, Y. Cheng, F. Ten, X. Wang, and Y. Ji. 2016. Fish hunting ankylosaurs (Dinosauria,Ornithischia) from the Cretaceous of China. Journal of Geology 40:183-190. 
Ji, S-A., L. Zhang, S. Zhang, and S. Hang. 2014. Large-sized ankylosaur (Dinosauria) from the Lower Cretaceous Jiufotang Formation of Western Liaoning, China. Acta Geologica Sinica - English Edition 88:1060-1065.

Thompson, R.S., J.C. Parish, S.C.R. Maidment, and P.M. Barrett. 2012. Phylogeny of the ankylosaurian dinosaurs

(Ornithischia: Thyreophora). Journal of Systematic Palaeontology 10:301-312.

Vickaryous, M.K., T. Maryańska, and D.B. Weishampel. 2004. Ankylosauria; pp. 363-292 in D.B. Weishampel, P. Dodson, and H. Osmólska (eds). The Dinosauria, 2nd edition. City: University of California Press, USA.

Xu, X., X.-L. Wang, H.-L. You. 2001. A juvenile ankylosaur from China. Naturwissenschaften 88:297-300.

Zheng, W-J. 2018. New ankylosaurid from the Cretaceous of China and the early evolution of Ankylosauridae.

University of Chinese Academy of Sciences. 290 pp.

\section{Ecomorphology of flight in the avian sternum}

\section{Talia M. Lowi-Merri ${ }^{1}$, Roger B.J. Benson², Santiago Claramunt ${ }^{3}$, and David C. Evans ${ }^{3}$}

${ }^{1}$ Department of Ecology \& Evolutionary Biology, University of Toronto, Toronto, ON, M5S 3B2, Canada; talia.lowi. merri@mail.utoronto.ca

${ }^{2}$ Department of Earth Sciences, University of Oxford, Oxford UK, OX1 3AN; roger.benson@earth.ox.ac.uk

${ }^{3}$ Department of Natural History, Royal Ontario Museum, Toronto, ON M5S 2C6;, Canada sclaramunt@rom.on.ca; davide@rom.on.ca

One of the most dramatic evolutionary transformations of the Mesozoic era was the evolution of birds (Aves) from paravian theropod dinosaurs. The origin of powered avian flight was a key innovation that expanded their ecological potential and led to a remarkable adaptive radiation. Today, birds display phenomenal morphological, ecological, and taxonomic diversity. A wide range of locomotory habits has evolved in the crown group of birds (Neornithes), including continuous flapping flight, intermittent bounding, soaring, wing-swimming, as well as flightless running. Despite extensive study of flight in both living and extinct birds, many aspects of its evolution remain unknown. Most research on the evolution of bird flight has focused on the wing, and less attention has been given to other parts of the skeleton, including the supportive elements of the pectoral girdle. The sternum is a single midline ossification, and forms the central portion of the pectoral girdle in birds. Flying birds possess a prominent bony projection, or keel, in the center of their sternum which serves as the attachment site for the major forelimb muscles associated with flight (pectoralis and supracoracoideus), and caudal processes on the sternum attach to abdominal muscles associated with the hip and thigh (obliquus abdominis externus and rectus abdominis). Morphological disparity in these portions of the sternum can be hypothesized to reflect the mechanical forces and muscle size in birds with differing flight and locomotory styles, but this has not been rigorously tested.

For the first part of this major project, we tested the ecomorphological relationship between the avian sternum and locomotory mode through a comprehensive comparison of sternal morphology across several families of modern birds. We performed a 3D geometric morphometric analysis from the sterna of 90 modern bird species, spanning over $70 \%$ of living bird orders, to quantify sternum morphological variation across extant bird taxa in order to assess the ecomorphology of locomotion through the use of principal component analysis (PCA). Our results show that flight styles requiring maneuverability or strong wing beats were not only correlated with a tall sternal keel, but a keel that possesses a starkly cranially-projecting apex. Narrow sterna with long caudolateral processes were present in birds that relied most on terrestrial locomotion, such as grouse and quails, while birds that both flapped continuously and perched on trees, such as passerines and cuckoos had broader sterna with short, wide caudolateral processes. 
Future analyses will apply this ecomorphological model to fossil paravian taxa, such as Confuciusornis, Ichthyornis, Sapeornis, and enantiornithines, in order to better understand the flight capabilities of taxa along the avian stem. This novel approach utilizing a 3D geometric morphometric framework of the avian sternum will provide new insights into the origin of powered flight within non-avian theropod dinosaurs. Clarification of the relationship between avian sternal form and function, as well as expanding our knowledge of flight structures beyond the wings alone, is necessary for testing ecological hypotheses surrounding flight capabilities in fossil taxa.

\section{The early history of dinosaur hunting in Canada (1874-1889)}

\section{Jordan C. Mallon ${ }^{1}$, Brigid E. Christison ${ }^{2}$, and Darren H. Tanke}

${ }^{1}$ Beaty Centre for Species Discovery and Palaeobiology Section, Canadian Museum of Nature, P.O. Box 3443, Station D, Ottawa, ON, K1P 6P4, Canada

${ }^{2}$ Department of Earth Sciences, Carleton University, 2115 Herzberg Laboratories, 1125 Colonel By Drive, Ottawa, ON, K1S 5B6, Canada

${ }^{3}$ Royal Tyrrell Museum of Palaeontology, P.O. Box 7500, Drumheller, AB, T0J 0Y0, Canada

The early history of dinosaur collecting in Canada during the 1870s and ' 80 s is poorly understood. Initial finds were made by the British North American Boundary Commission and the Geological Survey of Canada in Saskatchewan and Alberta but, beyond a few well-publicized examples (e.g., J.B. Tyrrell's Albertosaurus skull of 1884), little is known about what was found and where.

Most of this material is now housed at the Canadian Museum of Nature in Ottawa, and a recent survey of these historic finds allows for the first comprehensive narrative regarding their identity and procurement. The collection is heavily biased towards vertebral centra and phalanges, reflective of both taphonomic and collecting biases. Given current understanding of Late Cretaceous faunas of North America, hadrosaurids, ornithomimids, and small theropods are overrepresented, whereas ceratopsids and ankylosaurs are underrepresented. Fossils from the Belly River Group are best represented, after repeated visits to the area of present-day Dinosaur Provincial Park and (perhaps surprisingly, given the relative lack of subsequent prospecting there) Ross Coulee near Irvine, Alberta.

Careful identification of the material has yielded numerous first Canadian occurrences, in addition to some first global occurrences. The latter include the first ever occurrences of Dromaeosauridae (1881), Caenagnathidae (1884), and Thescelosauridae (1889).

The Upper Cretaceous fossil record of western Canada is among the richest in the world, and has been thoroughly studied over the last century. These fossils have informed our understanding of dinosaur behaviour, taphonomy, ecology, diversity dynamics, and extinction, among other aspects. But, like the animals themselves, the story of Canada's dinosaur-hunting legacy had humble beginnings-a story that has not been fully revealed before now. 


\section{Geometric morphometric analysis of the pedal claw of Confuciusornis sanctus and its implications for diet and behaviour}

\section{Annie P. McIntosh}

Department of Biological Sciences, University of Alberta, Edmonton, AB, T6G 2E9, Canada; apmcinto@ualberta.ca

Confuciusornis sanctus is an Early Cretaceous bird from the Liaoning Province of northeastern China. Although much work has been published on this species, details of its diet and behaviour remain unclear. Geometric morphometric analyses allow for the separation and comparison of specimens based on morphological variables. A geometric morphometric analysis was performed on the second pedal ungual of $C$. sanctus to determine how its morphology compares to that of extant birds and to elucidate details of its diet and behaviour. A total of 128 specimens was examined, comprising 104 extant bird species and C. sanctus. Three fixed landmarks and 50 sliding semilandmarks were used to define shape. A principal component analysis yielded a principal component one that explained 56\% of the variation among specimens and varies in the angle of claw curvature and sharpness of the claw tip. This, along with variation in centroid size, separates the extant taxa into three major behavioural groups: arboreal, terrestrial, and raptorial. The claw morphology of C. sanctus is dissimilar to extant raptorial birds, indicating that it was likely not using its claws to capture prey. Confuciusornis sanctus falls within the claw morphology of extant birds displaying arboreal behaviour, but is also similar to extant terrestrial birds. Additionally, the robust, toothless beak of C. sanctus is suited to a granivorous or piscivorous diet. Based on this, as well as reconstructions of the Jehol ecosystem as a heavily forested lacustrine environment, it is likely that $C$. sanctus spent most of its time foraging for seeds and invertebrates in densely wooded areas and fishes at the edges of shallow lakes. This indicates that $C$. sanctus may have been more of an omnivorous and opportunistic feeder, similar to modern crows. 


\section{When amber and dinosaurs meet: Amber from dinosaur bonebeds, and dinosaur remains preserved in amber}

\section{Ryan C. McKellar ${ }^{1,2}$, Lida Xing ${ }^{3}$, and Pierre F.D. Cockx ${ }^{1}$}

${ }^{1}$ Royal Saskatchewan Museum, and Biology Deptartment, University of Regina, 2445 Albert St., Regina, SK, S4P 4W7, Canada; ryan.mckellar@gov.sk.ca; pierre.cockx@laposte.net

${ }^{2}$ Department of Ecology \& Evolutionary Biology, 1501 Crestline Drive - Suite 140, University of Kansas, Lawrence, KS, 66045, USA

${ }^{3}$ State Key Laboratory of Biogeology and Environmental Geology, China University of Geosciences, Beijing, 100083,

China; xinglida@gmail.com

Amber was first reported from a dinosaur bonebed in 2004, as part of work on the Pipestone Creek

Pachyrhinosaurus bonebed, near Wembley, AB. Since this initial report, amber research has overlapped with dinosaur palaeontology in two different ways: (1) examining tiny pieces of amber from dinosaur bonebeds, (2) searching for inclusions of dinosaurs within larger amber pieces. The first major line of enquiry has been used extensively in western Canada to examine dinosaur bonebeds and the surrounding strata. By examining the chemical and geochemical characteristics of fossil plant resin, and searching for tiny inclusions within these amber samples, it has been possible to identify the resin-producing trees in the habitats surrounding bonebeds. This work also sheds some light on ecological conditions in ancient forests (e.g., precipitation patterns, and sources of plant stress). When amber is relatively abundant, a moderate diversity of insects and plant fragments provide further ecological clues and new species for palaeoentomology. The second major line of research has focused on rare inclusions of vertebrates within amber, based on deposits that produce larger, gem-quality amber pieces, such as mid-Cretaceous Burmese amber. Advancements in this line of research over the last five years have included the discovery of multiple enantiornithines (primitive toothed birds), a coelurosaur (non-avian theropod) tail fragment, numerous feather specimens, and a wider range of vertebrates, including snakes, lizards, and amphibians. These specimens have been biased toward smaller taxa and juvenile individuals, but preservation is unmatched elsewhere in the fossil record. The amber inclusions preserve microscopic details of soft tissues in three-dimensions, along with traces of original colour patterns and chemistry, faunal associations, and frozen behaviours. Ultimately, amber inclusions have confirmed many of the inferences drawn from fossils preserved in other settings. They have also refined our understanding of feather evolution, palaeobiogeography, and habitat use in the Cretaceous. Amber is becoming an increasingly valuable supplement to vertebrate palaeontology. 


\title{
Oldest known freshwater paracanthopterygian fish (Teleostei: Acanthomorpha) from the Maastrichtian of Alberta, Canada
}

\author{
Alison M. Murray ${ }^{1}$, Donald B. Brinkman², Michael G. Newbrey ${ }^{3}$, and \\ Andrew G. Neuman ${ }^{2}$ \\ ${ }^{1}$ Department of Biological Sciences, University of Alberta, Edmonton, AB, T6G 2E9, Canada; ammurray@ualberta.ca \\ ${ }^{2}$ Royal Tyrrell Museum of Palaeontology, Drumheller, AB, T0J 0Y0, Canada; don.brinkman@gov.ab.ca; andrew. \\ neuman@gov.ab.ca \\ ${ }_{3}^{3}$ Department of Biology, Columbus State University, Columbus, GA, 31907-5645, USA; newbrey_michael@columbusstate.edu
}

The Scollard Formation in the area of Dry Island Buffalo Jump Provincial Park in central Alberta has long been known to produce fish material. A particularly important locality sampling the Maastrichtian part of the formation has been named the Pisces Point locality for the many articulated fish specimens recovered. Pisces Point samples a palaeochannel with alternating sandstone and mudstone layers, which are interpreted as resulting from periodic alternation between active channel and stagnant waters in the channel. One of the articulated specimens recovered from Pisces Point is a small acanthomorph fish that represents the oldest articulated material of a paracanthopterygian recovered from freshwater deposits.

The specimen is placed in the Paracanthopterygii based on the presence of a full neural spine on the second preural centrum and two epurals in the caudal skeleton, two features that define the group. The presence of six branchiostegal rays indicate the fish can be further included in Percopsiformes. This order is usually considered to be monophyletic and contains three extant families, Percopsidae, Aphredoderidae, and Amblyopsidae, found in fresh waters of North America. Previously, the oldest known freshwater members of the order were Mcconichthys longipinnis from the early Palaeocene of Montana, and two taxa from the middle Palaeocene of Alberta, Massamorichthys wilsoni and Lateopisciculus turrifumosis both from the Paskapoo Formation. Additional fossil percopsiforms are present in the United States, with Trichophanes foliarum and T. copei from the Oligocene Florissant beds, and Amphiplaga brachyptera and Erismatopterus levatus from the Eocene Green River deposits. Libotonius blakeburnensis and L. pearsoni are percopsiforms from the Eocene of Canada and the USA.

Relationships among the percopsiform fishes are not clear, with numerous studies resulting in different groupings; however, most of these studies were designed to test broader relationships among the paracanthopterygians, rather than within the Percopsiformes. Until a phylogenetic analysis of the percopsiform taxa is done, we leave the new species from Pisces Point as incertae sedis within the order.

The articulated percopsiform from the Pisces Point locality allows isolated dentaries from vertebrate microfossil localities to be identified as being from a member of that group. These elements first appear in the late Campanian Judith River Group of Alberta and the Kaiparowits Formation of Utah, showing that percopsiforms were present in the Western Interior of North America at least 75 mya. 


\section{A brief history of Grande Prairie area palaeontology}

\section{Katalin M. Ormay, Robert N. Hunt, and Sheldon A. Graber}

Palaeontological Society of the Peace, Grande Prairie, AB, T8V 4C4, Canada; kormay@gprc.ab.ca; patnbert@telusplanet.net; sagraber@gmail.com

The first scientific account of the Grande Prairie region is from George Dawson of the Geological Survey of Canada. As part of the Survey's annual progress report for 1879, he described the geographical features of the land and named the Wapiti Formation as the "Wapiti River Sandstone". Interestingly, he did not mention dinosaur fossils. Frank Harris McLearn, also of the Geological Survey of Canada, worked in British Columbia's Peace Country, and in 1922 discovered dinosaur footprints in the Peace River Canyon by Hudson's Hope.

In the 1910-1940s, John Allan, Ralph Rutherford, Charles Stelck, and others mapped the Grande Prairie area and explored for coal, oil and gas, and investigated groundwater resources. The area was also explored by local residents and nature lovers during these decades. Some of them even acted as suppliers and guides to the geological exploration parties working in the region. Robert Cochrane (a local farmer), George Robinson (a surveyor and Prairie-Farm Assistance supervisor), and Dr. Lewis O’Brien (a physician and Member of the Legislative Assembly of Alberta) are but a few who had a keen interest in the fossils found in the rocks. They also promoted these resources to the scientific community. Robinson travelled the region and collected fossils extensively. He kept a meticulous catalogue of his collection which was acquired by the then Provincial Museum of Alberta in 1973. Christopher Collom described Robinson's collection as part of his dissertation in 2001. Bert Tieman, volunteer curator of the Grande Prairie Museum 1960s-1984, discovered fossils at Smoky Tower, southwest of Grande Prairie. Esox tiemani was named for him by Mark Wilson in 1980.

Dr. O'Brien together with Cochrane and others promoted the establishment of Kleskun Hills as a park. Cochrane, who homesteaded adjacent to Kleskun Hills, collected fossil bones on his land, and together with O'Brien concluded they found dinosaur fossils. Cochrane; however, never disclosed the exact location of his finds (hadrosaur postcranial elements), leaving this an unsolved mystery. Some of his finds are now on display in the Grande Prairie Museum. John Allan, working in the area in 1944, confirmed the Cochrane's fossils were Upper Cretaceous in age and originated from the Wapiti Formation and drew parallel with the fossils from the Red Deer river valley. Cochrane and his friends organized geological picnics in Kleskun Hills in the 1940-1950s with invited speakers from the University of Alberta or University of Calgary. Charles M. Sternberg visited Cochrane 1947 and commended his efforts in drawing attention to the fossil resources of the Grande Prairie area. Cochrane collected small fragments from Kleskun Hills, that Sternberg described as the lizard Chamops in 1951. This was the first scientific description of a vertebrate fossil in the Grande Prairie region.

Al Lakusta, a local high school science teacher, discovered dinosaur bone fragments along Pipestone Creek in 1972. Provincial Museum of Alberta palaeontologists tentatively identified the specimens as hadrosaur. Lakusta excavated at Pipestone Creek until his permit was revoked as the Historical Resources Act came into effect in 1974. At that time his collection was transferred to the Grande Prairie Museum. Dr. Philip Currie - en route to his Peace River Canyon, BC, research site - stopped by Grande Prairie Museum in 1979 and recognized the fossils belonging to a horned dinosaur. In 1985 Darren Tanke, technician at the Royal Tyrrell Museum (RTM), identified a nasal boss that had just been brought into the museum.

Grande Prairie Regional College (GPRC) and instructors, Drs. Bert Hunt (Engineering) and Desh Mittra (Geology) assisted with a Provincial Museum of Alberta excavation and preparation of an early Holocene elk from a gravel pit along the Smoky River in 1984-1985. The publicity surrounding their involvement generated more local landowners coming forward with fossils finds and a growing interest in the palaeontology of the area.

One of the first field projects of the newly established Royal Tyrrell Museum (then Tyrrell Museum of Palaeontology) was the opening of the Pipestone Creek Bonebed in 1986. 
GPRC's Bert Hunt acted as an engineer monitoring slope stability at the Pipestone Creek excavation in 1987. His involvement developed into volunteering with excavating and preparing fossils. Hunt, occasionally accompanied by Mittra, and through them GPRC, provided substantial assistance to the Pipestone Creek excavations in 1987, 1988, 1989. Hunt was the first on record suggesting a palaeontology museum to be established in the city. Beside the excavations, Hunt and other volunteers participated in the exploration of the area, worked closely with Tanke of the RTM, and ensured the local communities were well informed of the significance of the paleontological work.

Bert Hunt continued with the exploration of the region even after the Pipestone Creek excavations closed down in 1989. He was a Paleo Trustee of the RTM, and organized and lead public education events. Numerous fossil locations were discovered and monitored by him. Regular updates were sent to the Tyrrell Museum.

The 2002 excavation of a Pachyrhinosaurus skull with an attached parietal horn, and the 2003 excavation of new saurolophine material from Red Willow Gardens by the RTM generated renewed interest in the fossils of the area. GPRC were instrumental facilitating these endeavors by mobilizing local assistance and by participating in the excavations.

The Palaeontological Society of the Peace was established in 2004 by local volunteers, led by Drs. Desh Mittra and Bert Hunt. The society's efforts of public education and linking local volunteers to the scientific community was encouraged and facilitated by GPRC. The Society's goal was to make known the opportunities for discoveries in the Grande Prairie region: unexplored outcrops along the waterways, the relatively unknown stratigraphy and the unique setting of the Wapiti Formation within the Upper Cretaceous environments indicated possibilities for discovering new species and completing palaeoenvironmental and palaeogeographical studies. Tanke published a summary of the then known outcrops and fauna of the Grande Prairie region in 2004. The monograph, describing the new species of horned dinosaur Pachyrhinosaurus lakustai from the Pipestone Creek bonebed by Philip J. Currie, Wann Langston Jr, and Darren H. Tanke was published in 2008 and revealed at GPRC. Currie and his team, and Federico Fanti from the University of Bologna have been working in the area since 2004; their published results are drawing more researchers to the area and are leading to more discoveries and publications.

GPRC partnered with the County of Grande Prairie \#1 (2009-2012) to build capacity for Grande Prairie area Palaeontological exploration, education and tourism initiatives (Rural Alberta Development Fund - Pipestone Creek Dinosaur Initiative). This project laid the groundwork for establishing the Philip J Currie Dinosaur Museum. Roy Bickell, as an amateur fossil hunter amassed a large collection of marine fossils from the Grande Prairie region. He donated part of his collection to local museums, to GPRC and to the Philip J. Currie Dinosaur Museum. Bickell was an active an instrumental member of the local initiatives of planning for the Museum.

The Museum, and the increasing number of research projects, and the large number of scientific papers of the last decade show that the Grande Prairie Region is indeed the next frontier for palaeontological discoveries in Alberta. 


\section{Discrete variation in maxillae of eudromaeosaur dinosaurs and its relation to trends in snout morphology}

\section{Mark J. Powers and Philip J. Currie}

Department of Biological Sciences, University of Alberta, Edmonton, AB, T6G 2E9, Canada; powers1@ualberta.ca

Dromaeosaurids were small to medium sized theropod dinosaurs that occupied the small predator niche during the Late Cretaceous on nearly every continent. Due to their small sizes, their fossil remains are quite rare compared to contemporaneous large-bodied taxa. However, articulated skeletons of small-bodied dromaeosaurids are known from Asia, and include skeletons of Linheraptor, Tsaagan, and Velociraptor. Due to the scarcity of fossil material in places like North America, numerous species have been described from isolated elements. One of the most diagnostic elements in dromaeosaurid taxonomy is the maxilla. This element has been further used to generate hypotheses of snout morphology in taxa which are only represented by a maxilla and few other cranial bones. The preantorbital body of the maxilla has been used in distinguishing short or long snouted morphology and infer affinities between geographically separated groups. Snout morphology is important to examine as it may have implications for ecological and taxonomic relationships.

To test if proportional characters can be used confidently to identify distinct taxa within Dromaeosauridae, up to 14 measurements were taken from 15 available dromaeosaurid maxillae across ten species, and a troodontid specimen for outgroup comparison. Most specimens are members of Eudromaeosauria, a clade of dromaeosaurids excluding species from the subfamilies Microraptorinae and Unenlagiinae. The measurements were run through bivariate and multivariate analyses to look for natural breaks in the data. Analyses of maxillae reveal trends in proportionate measurements, which form natural group within Eudromaeosauria that generally distinguish Asian and North American taxa from each other. Preantorbital body length/height ratios show that North American taxa have preantorbital bodies that are dorsoventrally taller than they are anteroposteriorly long. This contrasts with the Asian taxa where the preantorbital body is consistently longer than tall. While examining overall length and height dimensions of maxilla, North American taxa have maxillae that are approximately two times longer than tall, whereas in Asian taxa the maxillae are 2.5 to 3 times longer than they are tall. These proportions seem to be consistent between North American and Asian taxa except for the North American taxon Acheroraptor. Although the most posterior portion of the jugal ramus is missing, the preserved maxillary proportions in this taxon are like those of other North American taxa; however, the preantorbital body has closer proportions to the sampled Asian taxa. The preantorbital body length/height ratio is therefore not a good indicator of snout elongation in eudromaeosaurs, whereas the same ratio of the maxilla is more reliable in making such inferences. Within Eudromaeosauria, elongation of the snout is limited to Velociraptor and its close relatives. Given the geographical separation from North American representatives, and the contrast in faunal assemblages, the snout elongation in Asian taxa likely served a functional adaptation for acquiring prey, different from contemporaneous North American relatives. 


\title{
Faunal composition and turnover during the late Pleistocene of Medicine Hat, Alberta
}

\section{Ashley R. Reynolds ${ }^{1}$ and Kevin L. Seymour ${ }^{2}$}

\author{
${ }^{1}$ University of Toronto, Department of Ecology and Evolutionary Biology, 100 Queen's Park, Toronto, ON, M5S 2C6, \\ Canada; ashraereynolds@gmail.com \\ ${ }^{2}$ Royal Ontario Museum, Department of Natural History, Toronto, ON, M5S 2C6, Canada; kevins@rom.on.ca
}

During the 1960s and 1970s, C.S. Churcher and A. MacS. Stalker led several field expeditions to the Canadian prairies, with the purpose of studying the Plio-Pleistocene stratigraphy and vertebrate faunas of the region. As part of this project, they collected over 1,200 vertebrate fossils from nearly two dozen localities in the area immediately surrounding the city of Medicine Hat, Alberta. These localities span the Irvingtonian and Rancholabrean land mammal ages, allowing for study of faunal turnover throughout the Late Pleistocene. Additionally, recent work has suggested that Beringian taxa such as the Beringian wolf ecomorph (Canis lupus) and the cave lion (Panthera spelaea) may have migrated through the area between the Cordilleran and Laurentide ice sheets. Further study of the late Pleistocene Medicine Hat fauna may uncover additional instances of Beringian taxa outside their usual range. The purpose of this study is to provide an overview of the faunal composition of fossil localities in the Medicine Hat area based on material held at the Royal Ontario Museum, and to outline potential areas for future research.

Across all localities, Equus is the dominant taxon, representing between 43-69\% of the specimens collected from the six localities with $>50$ collected specimens. At most of these six localities, Camelops is the second most common taxon, making up 9-30\% of specimens collected. The exception is Lindoe Bluff, where Bison, representing 20\% of specimens, is more commonly found than Camelops, which is the third most abundant taxon. Only about $14 \%$ of specimens have associated biostratigraphic records but based on these data some broad patterns in faunal turnover can be inferred. Equus comprises between 40-61\% of the recovered fauna throughout the sequence, but there appears to be a drop in the abundance of Camelops between the Sangamonian interglacial and the Wisconsinan glacial period. There is a marked increase in Bison occurring following the Wisconsinan glaciation, which is likely why it is the second most common taxon at Lindoe Bluff, from which many postglacial specimens were collected.

These data suggest that future work on the fossil faunas of Medicine Hat could yield valuable information regarding faunal turnover during and at the end of the Pleistocene. However, this will require more precise taxonomic identifications and the collection of additional specimens with tight stratigraphic control. Recently, the authors revisited the Surprise Bluff locality and recovered several fossils, including an elephantid caudal vertebra. Future field expeditions will be conducted at this and other Medicine Hat localities, with the goal of clarifying the composition of, and temporal variation in, the region's fauna. In particular, we conduct sampling specifically for microvertebrates, which were likely under-sampled during original collection efforts. 


\section{Revisiting the evolution of maniraptoran pelvic musculature}

\section{Matthew M. Rhodes and Philip J. Currie}

Department of Biological Sciences, University of Alberta, Edmonton, AB, T6G 2E9, Canada; mmrhodes@ualberta.ca; pjcurrie@ualberta.ca

Theropod dinosaurs retained bipedalism throughout their evolutionary history, a constraint inherited by their avian descendants. Many groups additionally exhibit adaptations for enhanced running ability (cursoriality). However, plesiomorphic theropods achieve bipedalism with an upright posture, centre of mass near the hip joint, and close association with caudal musculature. In contrast, birds have a crouched posture to accommodate the shift of the centre of mass far anterior to the hip and terrestrial locomotion driven by intrinsic pelvic and limb muscles. Tail reduction, decoupling of tail and leg modules, and anterior migration in centre of mass generally follow a gradual, stepwise pattern. Recent studies show that these trends accelerated within Maniraptora prior to the evolution of birds.

Reconstruction of theropod pelvic musculature provides an alternative perspective on the trends in locomotory evolution based on skeletal features, and tracks the proportion of tail and leg muscles. Whereas close maniraptoran relatives (ornithomimids and tyrannosaurids) retain large caudal muscles, basal therizinosaurs show strong reduction, suggesting a somewhat abrupt onset of caudal decoupling rather than gradual decline. Caenagnathids show a similar pattern, which challenges traditional views of this family as highly cursorial based on skeletal data. Conversely, pelvic myology of plesiomorphic and derived troodontids reinforces a highly cursorial habit in the latter, which was acquired secondarily and more reliant on intrinsic hip and leg muscles than that of the tail in comparison to other highly cursorial theropods. Although the evolution of locomotory musculature on the line to birds is generally considered a stepwise progression, muscle reconstruction highlights occasional punctuated shifts and unforeseen convergence. 


\section{Embryonic and hatchling ankylosaurs from the Campanian of Bayan Mandahu (Inner Mongolia, People's Republic of China) and Hermiin Tsav (Mongolia)}

\section{Robin L. Sissons ${ }^{1}$, Philip J. Currie ${ }^{1}$, Michael E. Burns², Victoria M. Arbour ${ }^{3}$, Yuong-Nam Lee ${ }^{4}$, and Dong Zhiming ${ }^{5}$}

${ }^{1}$ Department of Biological Sciences, University of Alberta, Edmonton, AB, T6G 2E9, Canada; pjcurrie@ualberta.ca; robins@ualberta.ca;

${ }^{2}$ Department of Biology, Jacksonville State University, Jacksonville, AL, USA; mburns@ualberta.ca

${ }^{3}$ Royal BC Museum, Victoria, BC, Canada; varbour@royalbcmuseum.bc.ca

${ }^{4}$ Seoul National University, Seoul, South Korea; ynlee@snu.ac.kr

${ }^{5}$ Institute of Paleontology and Paleoanthropology, Chinese Academy of Sciences, Beijing 100044, China

Embryonic and hatchling dinosaur specimens were collected in 1988 and 1990 during the Sino-Canadian Dinosaur Project expeditions in the Campanian redbeds of the Bayan Mandahu Formation (Inner Mongolia, China). Furthermore, several elements of juvenile ankylosaurs were collected from the Nemegt Formation of Hermiin Tsav 1, Mongolia, in 2008 during the Korean-Mongolian International Dinosaur Project expedition. Cranial and postcranial material of one ankylosaur from Bayan Mandahu, and postcranial material of multiple ankylosaurs from Hermiin Tsav are Late Cretaceous in age. A partial cranium and postcranial skeleton of a hatchling ankylosaurian - cf. Pinacosaurus - includes small osteoderms, which may represent the beginnings of the cervical half rings that are usually already well ossified in juvenile individuals from China and Mongolia that are longer than $1.5 \mathrm{~m}$. The hatchling material from Hermiin Tsav likely represents either Saichania or Tarchia, although taxonomic identification of juvenile postcranial remains is challenging. These elements represent the smallest yet known ankylosaurs, with at least two individuals preserved. Because they were found in association with each other, either multiple eggs from a single nest hatched at the same time, or the eggs hatched penecontemporaneously from multiple nests. These specimens therefore provide an important window into earlier ontogenetic stages that are rarely preserved in dinosaurs. 


\section{Systematics of tethysaurine mosasauroids}

\section{Erin G. St Jean and Michael W. Caldwell}

Department of Biological Sciences, University of Alberta, Edmonton, AB, T6G 2E9, Canada

Tethysaurus nopcsai is a basal mosasauroid from the early Turonian. In previous cladistic analyses, it has been placed in the clade Tethysaurinae with Pannoniasaurus. Two specimens (UALVP 48850 and UALVP 55738), which have previously been attributed to Tethysaurus, were described and characterized. These specimens each comprise articulated skulls and the first three cervical vertebrae. Both specimens were compared to T. nopcsai. For the comparison, only the holotype (MNHN GOU 1) of T. nopcsai was used. The original description of $T$. nopcsai included two other specimens (MNHN GOU 2 and MNHN GOU 3); these specimens were excluded from this comparison because specific diagnostic characters (e.g., quadrate morphology) differ enough in these specimens compared to the holotype to question their classification as T. nopcsai. With the removal of the referred specimens from the description of T. nopcsai, it was necessary to recode some characters in the character matrix to reflect any morphological differences between the holotype and referred specimens. Cladistic analysis resulted in the removal of Pannoniasaurus from Tethysaurinae, as well as a polytomy between UALVP 48850, Russellosaurus, Romeosaurus, and a group containing Tethysaurus and UALVP 55738. The reason for the removal of Pannoniasaurus from Tethysaurinae is unclear and more work will need to be done to understand this result.

\section{Tracking dinosaurs: Using modern technology to engage with prehistory}

\section{Yukiko Stranger-Galey ${ }^{1}$, Richard $\mathrm{McCrea}^{2}$, and Lisa Buckley ${ }^{2}$}

${ }^{1}$ Beaty Biodiversity Museum, University of British Columbia, Vancouver, BC, V6T 1Z4, Canada; yukiko.strangergaley@ubc.ca

${ }^{2}$ Peace Region Palaeontology Research Centre

When you think of dinosaurs you might think of Alberta. But BC has a rich and exciting prehistory that, in part due to its landscape, remains largely hidden. The Beaty Biodiversity Museum and the Peace Region Palaeontological Research Centre have recently worked in close collaboration to develop an exhibit that shares some of the rich biodiversity of our prehistoric environment with our public. This new permanent exhibit (Fig. 1) showcases three dinosaur trackway casts from B.C. and explores the stories evoked by these footprints in time. This partnership between our two institutions is making fossils more accessible to the community and inspires a greater understanding of biodiversity and the interconnectedness of all life, past, present, and future.

The three trackway casts in the exhibit include four distinct dinosaur footprint tracks: Mist Mountain Trackway (unidentified isp., 140 mya), Minnes Group Trackway (Megalosauripus isp., 130 mya and Iguanodontipus isp., 130 mya) and Ankylosaur Trackway (Tetrapodosaurus isp., 93-97 mya). Through these trackways and associated signage (Fig. 2) we are able to engage the public in understanding evolutionary pathways that connect dinosaurs to modern species, exploring prehistoric life as part of an ecosystem and not as species in isolation, and appreciating that research and new discoveries in this field are current and ongoing with continuing impact today. The exhibit invites the public to gently touch these trackways (Figs. 3 and 4), and this physical touch creates an intimate connection between visitor and extinct creature that spans the millions of years between them.

Our project team worked closely together for several years, yet members from these two institutions never met 


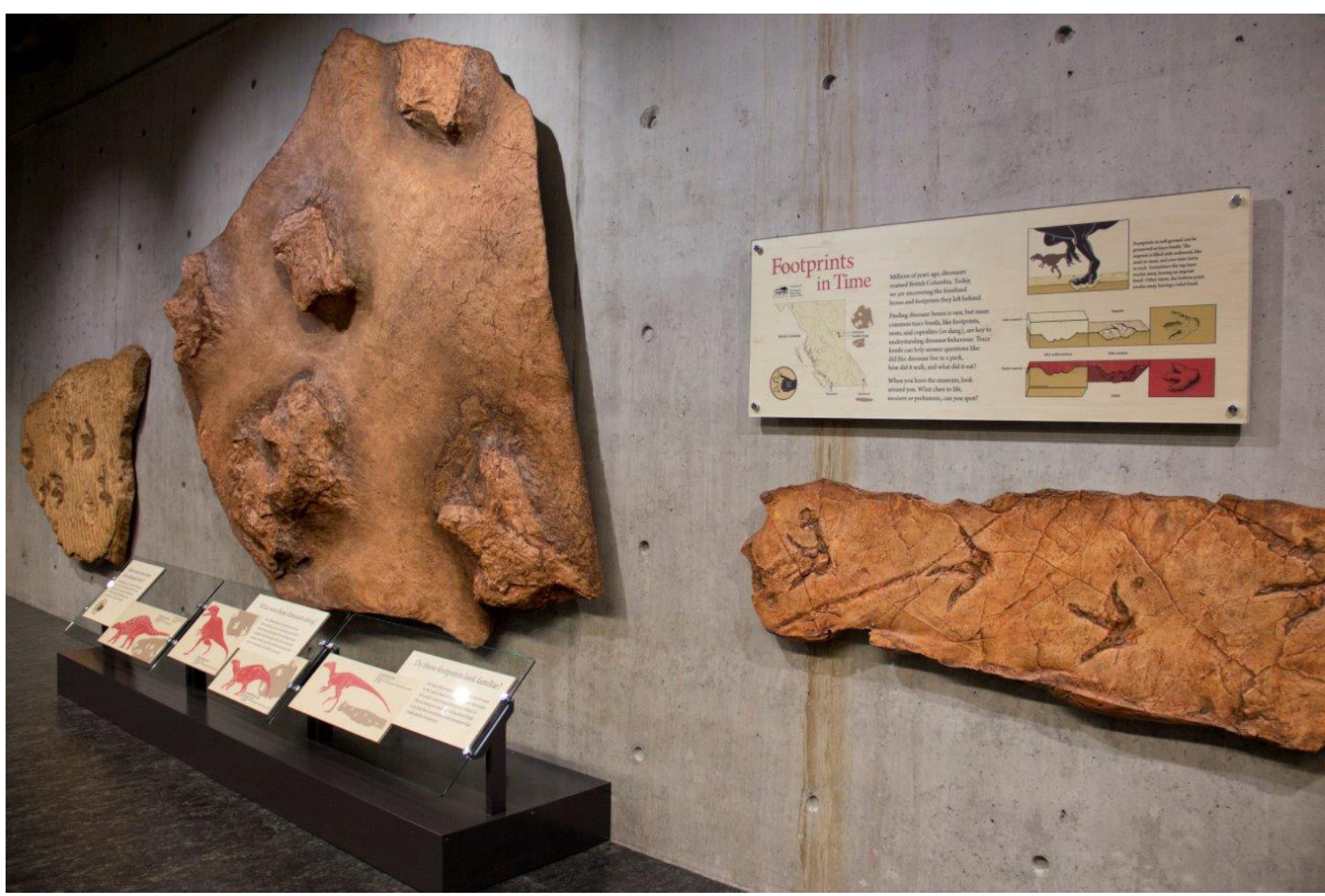

Figure 1. Footprints in Time exhibit at the Beaty Biodiversity Museum.

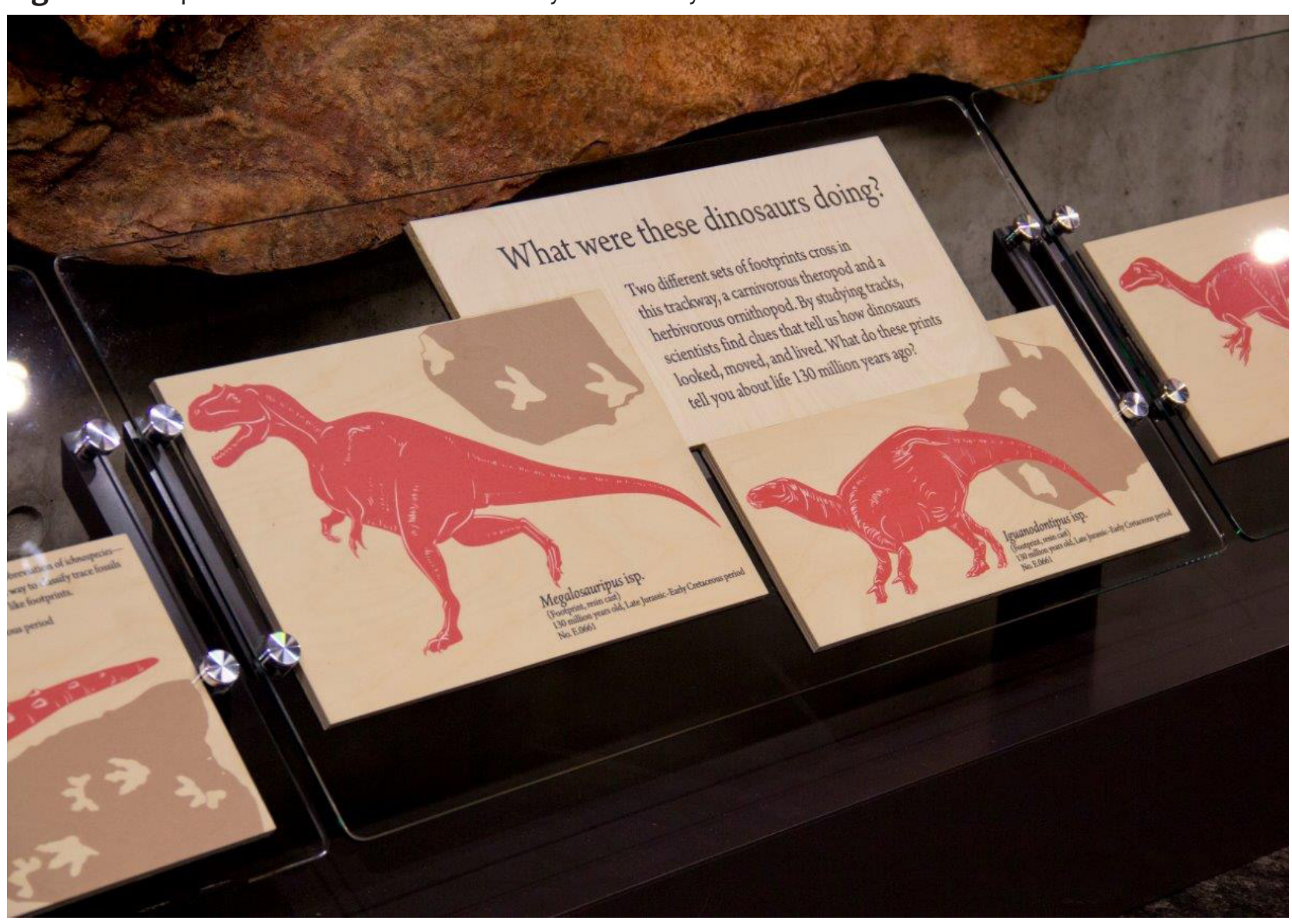

Figure 2. Detail of the Footprints in Time exhibit, showing the stories that the exhibit shares. 
in person until after the exhibit was installed and completed. We will share the strategies that we used to connect our communities through the digital realm. We will also invite delegates to explore our early-stage development of an online digital experience dedicated to bringing visitors, through technology, to rarely-seen dinosaur fossil sites from BC and across Canada. When there is no real-life audio or video of dinosaurs to draw from to instantly immerse visitors in an environment, what digital strategies can be utilised to engage visitors at the same emotional level? We will present interactive options that we are considering with reasoning behind the decisions we are making, and invite you to weigh in on this still fluid exhibit.

By the end of this session, conference delegates will:

- Understand strategies, including the effective use of technology, for the collaborative development of exhibits and programs across great physical distance.

- Gain insight into how technology can activate a topic where there is no real-life audio or video to draw from.

- Explore a suite of technological options for creating a dynamic and immersive digital online exhibit.

Figures 3 and 4 . Visitors are invited to engage with the exhibit through touch
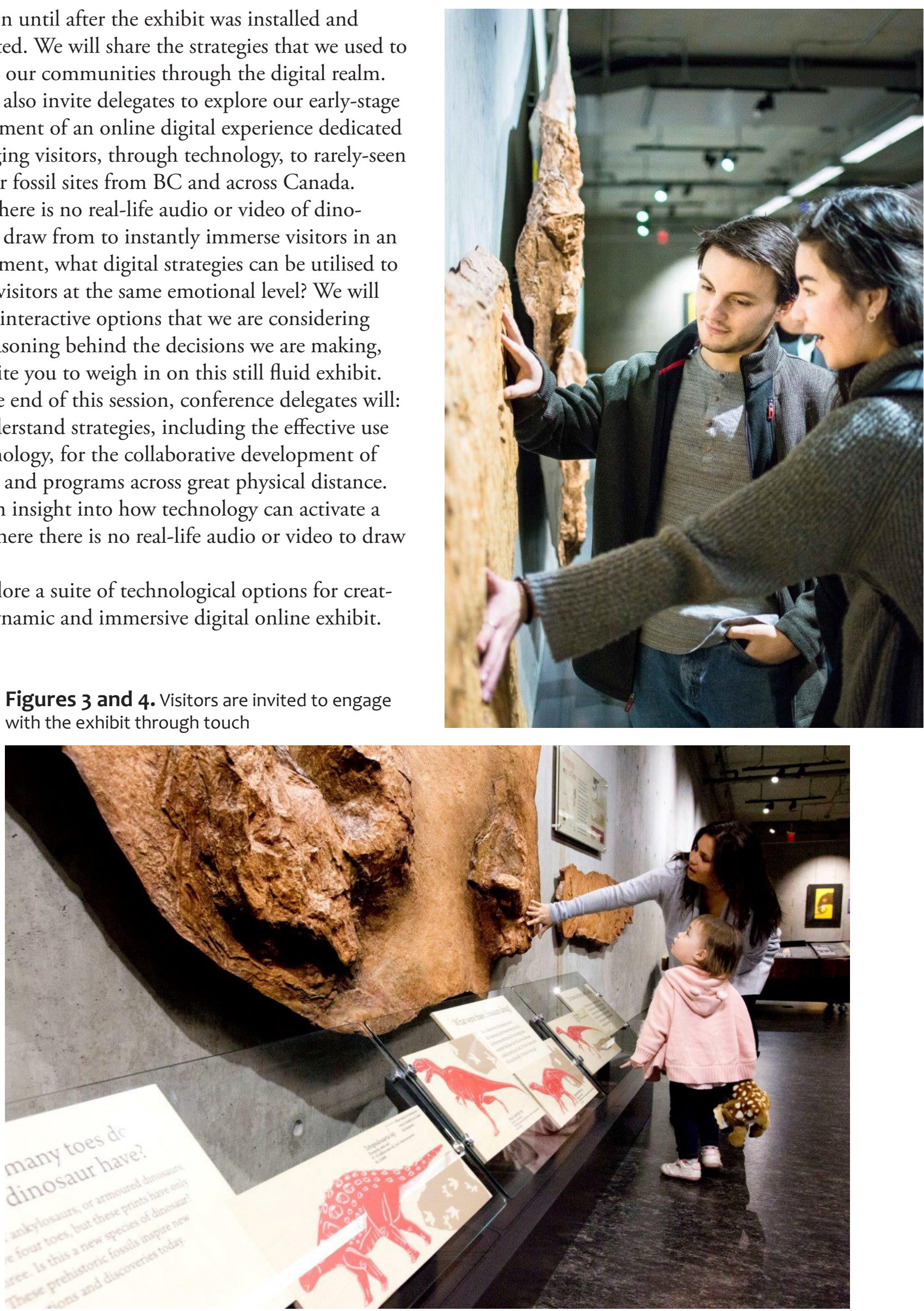


\title{
A young juvenile elasmosaur skull from the Upper Cretaceous Bearpaw Formation of Saskatchewan
}

\author{
Hallie P. Street ${ }^{1}$, Michelle M.C. Mekarski ${ }^{2}$, Emily L. Bamforth ${ }^{1}$, and \\ Hans C. Larsson ${ }^{3}$ \\ ${ }^{1}$ Royal Saskatchewan Museum, T. rex Discovery Centre, P.O. Box 460, Eastend, SK, S0N 0T0, Canada \\ ${ }^{2}$ University of Ottawa, Department of Biology, Grendon Hall Room 160, 30 Marie Curie, Ottawa, ON, K1N 6N5, Canada \\ ${ }^{3}$ Redpath Museum, McGill University, 859 Sherbrooke St. West, Montreal, QC, H3A 2K6, Canada
}

We report on the discovery of a very young elasmosaur skull from the Campanian Bearpaw Formation of Saskatchewan. The skull was discovered by amateur fossil hunters along the banks of the South Saskatchewan River. Many of the fossils recovered from the site - both vertebrate and invertebrate, and including the elasmosaur skull - are preserved within concreted nodules. The fauna associated with the elasmosaur skull includes ichthyodectids, crustaceans, ammonites, and a variety of bivalves. The site also yields trace fossils such as Ophiomorpha isp.

The skull is identified as an early ontogenetic stage both by its small size and the extremely low degree of ossification of the cranial bones. Juvenile plesiosaur fossils have also been recovered from a bonebed near Herschel, Saskatchewan that was deposited in the Dinosaur Park Formation - Bearpaw Formation transition, though the preservation at the two sites differs greatly. The lower-most strata associated with the Bearpaw Transgression across western Saskatchewan are interpreted to have been deposited in a barrier island system (Gilbert et al., 2019). A shallow, silled basin would have provided an ideal environment for plesiosaurs to give birth and raise their young.

One of the only elasmosaurid taxa for which a similarly young ontogentic stage is known is Tuarangisaurus keyesi from the Upper Cretaceous of New Zealand. Observations of the juvenile and adult skulls from that species indicate that elasmosaurid cranial elements do vary with ontogeny (Otero et al. 2018). Comparing this newly discovered skull to those of known elasmosaurs from the Bearpaw formation (Nakonanectes bradti from Montana and Terminonatator ponteixensis from Saskatchewan) will help elucidate how consistent ontogenetic patterns are across Elasmosauridae.

\section{Literature Cited}

Gilbert, M.M., L.A. Buatois, and R.W. Renaut. 2019. Ichnology and depositional environments of the Upper Cretaceous Dinosaur Park - Bearpaw formation transition in the Cypress Hills region of Southwestern Saskatchewan, Canada. Cretaceous Research. https://doi.org/101016/j.cretres.2018.12.017

Otero, R.A., J.P. O’Gorman, W.L. Moisley, M. Terezow, and J.A.W. McKee. 2018. A juvenile Tuarangisaurus keyesi Wiffen and Moisley 1986 (Plesiosauria, Elasmosauridae) from the Upper Cretaceous of New Zealand, with remarks on its skull ontogeny. Cretaceous Research 85:214-231. 


\section{A new species of plioplatecarpine mosasaur (Squamata: Mosasauridae) from the Late Cretaceous of Morocco, with a re-evaluation of the problematic taxon 'Platecarpus' ptychodon}

\section{Catherine R.C. Strong ${ }^{1}$ and Michael W. Caldwell ${ }^{1,2}$}

${ }^{1}$ Department of Biological Sciences, University of Alberta, Edmonton, AB, T6G 2E9, Canada; crstrong@ualberta.ca ${ }^{2}$ Department of Earth and Atmospheric Sciences, University of Alberta, Edmonton, AB, T6G 2E9, Canada; michael.caldwell@ualberta.ca

Mosasaurs were a dominant group of marine reptiles during the Late Cretaceous, noted for their worldwide adaptive radiation during the latter stages of this period. The Maastrichtian phosphates of Morocco in particular record a diverse assemblage of numerous mosasaur genera, thus exemplifying the remarkable capacity for evolutionary radiation present in this family.

This study builds on our knowledge of this diversity via the description and analysis of a new mosasaur specimen (UALVP 57048) from Morocco, consisting of relatively complete cranial and isolated postcranial material. The teeth of this specimen resemble those of 'Platecarpus' ptychodon, suggesting referral to this species; however, due to critical flaws regarding the original diagnosis of ' $P$.' ptychodon which have gone unaddressed in recent research, we re-examine its fundamental validity as a species. We ultimately argue for its rejection based on the non-diagnostic nature of its holotype material and diagnosis, thus precluding the referral of UALVP 57048 to this taxon.

Phylogenetic analysis under multiple parsimony-based methods consistently recovers UALVP 57048 as the sister group to Selmasaurus russelli, with these taxa forming a clade within the Plioplatecarpinae alongside $S$. johnsoni and Goronyosaurus nigeriensis. We therefore propose that UALVP 57048 represents a new species of Selmasaurus, making it the first member of this genus from outside North America. Features uniting this specimen with Selmasaurus include a distinctly laterally deflected quadrate shaft and a highly constricted parietal table, the latter of which is also present in $G$. nigeriensis. This new species is distinguished from other Selmasaurus species by a large and oval-shaped pineal foramen which contacts the frontoparietal suture, a wide postorbitofrontal, and certain vertebral features. It is also characterized by a highly elongate snout, highly retracted nares, large supratemporal foramina, and a dentary in which the medial parapet is taller than the lateral dentary wall.

Both Selmasaurus and Goronyosaurus have only rarely been included in mosasaur or squamate phylogenies, and never in the same analysis in the published literature. As such, recovery of the aforementioned Goronyosaurus + Selmasaurus + UALVP 57048 clade provides novel insight into plioplatecarpine evolution. All of these taxa inhabited ecosystems rich in other mosasaur species from a variety of subfamilies. Cranial features shared by this clade - including snout elongation and akinetic cranial sutures - potentially reflect morphological specialization into distinct ecological and predatory niches to reduce competition and enable this coexistence. 


\section{Cranial ontogeny of Thamnophis radix (Serpentes: Colubroidea) provides novel insights into snake skull evolution}

\section{Catherine R.C. Strong ${ }^{1}$, Tiago R. Simões ${ }^{1}$, Michael W. Caldwell ${ }^{1,2}$, and Michael R. Doschak ${ }^{3}$}

${ }^{1}$ Department of Biological Sciences, University of Alberta, Edmonton, AB, T6G 2E9, Canada; crstrong@ualberta.ca; tsimoes@ualberta.ca

${ }^{2}$ Department of Earth and Atmospheric Sciences, University of Alberta, Edmonton, AB, T6G 2E9, Canada; michael.caldwell@ualberta.ca

${ }^{3}$ Faculty of Pharmacy \& Pharmaceutical Sciences, University of Alberta, Edmonton, AB, T6G 2E1, Canada; mdoschak@ualberta.ca

Accurate knowledge of skeletal ontogeny in extant organisms is crucial in understanding the structure and evolution of important morpho-functional systems and in enabling inferences of the ontogenetic stage of fossil specimens. However, detailed knowledge of skeletal ontogeny is lacking for most squamates, including snakes. Very few studies have discussed postnatal development in snakes, with none incorporating data from all three major ontogenetic stages - embryonic, juvenile, and adult. Here, we provide the first analysis encompassing these three ontogenetic stages for any squamate, using the first complete micro-computed tomography (micro-CT)based segmentations of an embryonic snake skull.

This analysis reveals new information regarding the evolution of macrostomy (large-gaped feeding) and of the snake braincase. The most significant ontogenetic changes involve the feeding apparatus, with major elongation of the tooth-bearing elements and jaw suspensorium causing a posterior shift in the jaw articulation. This shift enables macrostomy and occurs in Thamnophis radix via a developmental trajectory different than is typical of other macrostomatans, indicating the evolution of macrostomy to be more complex than previously thought. Progressive changes in the dorsal articulation of the quadrate - from articulating with both the prootic (chondrocranial) and supratemporal (dermatocranial) bones in the embryo to just the supratemporal in the adult - enable comparison of the skull of $T$. radix to that of scolecophidian snakes, in which the supratemporal is absent or highly reduced and the quadrate articulates only with the chondrocranium throughout life. The ontogenetic changes seen in $T$. radix indicate the scolecophidian morphology to be paedomorphic, representing a retention of the embryonic articulation between the quadrate and the chondrocranium. Finally, the braincase of T. radix is evolutionarily unique among colubroids in lacking a crista circumfenestralis, a structure previously thought to be universally present among these derived snakes. This absence is considered herein to represent paedomorphic retention of the embryonic condition in which the crista circumfenestralis is undeveloped. The presence of this presumably 'basal' morphology in an otherwise highly derived taxon highlights the need for further research into the structure and evolution of the snake braincase. Through this ontogenetic analysis, we thus present several important challenges to current paradigms regarding snake cranial evolution. 


\section{A juvenile lambeosaurine dinosaur from the Upper Cretaceous Wapiti Formation of northern Alberta}

\section{Corwin Sullivan ${ }^{1,2}$, Nicolás Campione ${ }^{3}$, Phil Bell ${ }^{3}$, Robin Sissons ${ }^{1}$, Federico Fanti ${ }^{4}$, Matthew Vavrek ${ }^{5}$, and Derek Larson ${ }^{2}$}

\footnotetext{
${ }^{1}$ Department of Biological Sciences, University of Alberta, Edmonton, AB, T6G 2E9, Canada; corwin1@ualberta.ca; robin.sissons@gmail.com

${ }^{2}$ Philip J. Currie Dinosaur Museum, Wembley, AB, T0H 3S0, Canada; dlarson@dinomuseum.ca

${ }^{3}$ School of Environmental and Rural Science, University of New England, Armidale, New South Wales 2351, Australia; pbell23@une.edu.au; nicolas.campione@gmail.com

${ }^{4}$ Dipartimento di Scienze della Terra e Geologico-Ambientali, Alma Mater Studiorum, Università di Bologna, 40216

Bologna, Italy; federico.fanti@unibo.it

${ }^{5}$ Grande Prairie, T8W 2L5, Canada; matthew@matthewvavrek.com
}

The Campanian to Maastrichtian Wapiti Formation of northern Alberta preserves a rich vertebrate fauna notably including fish, turtles, champsosaurs, lizards, dinosaurs, and mammals. However, this assemblage remains less thoroughly explored than its roughly coeval equivalents in southern Alberta and the western United States, partly because the forested terrain of the northern part of the province largely restricts areas of outcrop to river valleys. More fully documenting the relatively high-latitude vertebrate fossils of the Wapiti Formation represents an important step in piecing together the four-dimensional puzzle of Late Cretaceous faunal variation in Laramidia.

Recent fieldwork undertaken near Grande Prairie resulted in the discovery of a partial skeleton of a lambeosaurine hadrosaurid dinosaur with a nearly complete skull at the DC Bonebed, a river channel deposit in the middle part (Unit 3) of the Wapiti Formation. Dating of bentonite layers within Unit 3 suggests the DC Bonebed is approximately coeval with the transition in the southern Alberta record from the Bearpaw Formation to the overlying Horseshoe Canyon Formation, an interval characterised by poor sampling of terrestrial vertebrates.

The DC specimen is a juvenile in which the cranial crest typical of lambeosaurines is only incipiently developed. The nasal is anteriorly bifurcated into dorsal and ventral processes, as in the closely related genera Hypacrosaurus and Corythosaurus but in contrast to the condition in Lambeosaurus. Furthermore, both a principal components analysis of 12 linear measurements $(\mathrm{N}=59)$ and a bivariate plot of crest-snout angle vs. skull length $(\mathrm{N}=52)$ for all three genera show that the skull proportions of the DC lambeosaurine are inconsistent with those of Hypacrosaurus, though potentially consistent with both Corythosaurus and Lambeosaurus. The DC lambeosaurine also resembles Corythosaurus and Lambeosaurus, and differs from Hypacrosaurus, in the shape of the lacrimal. Taken together, these characteristics seem most compatible with identification of the specimen as at least close to Corythosaurus, a well-represented genus in the southern Alberta record.

Nevertheless, the DC lambeosaurine resembles Hypacrosaurus rather than Corythosaurus in the anteroposterior shortness of the narial opening (shared with $H$. altispinus, although not $H$. stebingeri), the shape of the posterolateral process of the premaxilla, and the fact that the fontanelle (an unossified gap in the lateral side of the crest) is partially closed despite the specimen's juvenile status. The nasal and premaxilla barely exclude the prefrontal from the margin of the fontanelle, a condition arguably intermediate between Corythosaurus and Hypacrosaurus. Furthermore, the nasal of the DC lambeosaurine is unusual and potentially autapomorphic in that the ventral process is itself bifurcated, giving the anterior end of the nasal a trident-like morphology, and divides the fontanelle into two smaller gaps of unequal size.

Although the resemblances to Corythosaurus are compelling, the DC lambeosaurine differs in important respects from typical members of this genus, including those representing a comparable ontogenetic stage. It may 
represent either an unusual individual of Corythosaurus or a member of a distinct Wapiti Formation taxon, albeit one undoubtedly closely related to both Corythosaurus and Hypacrosaurus. This uncertainty highlights the difficulty of determining which anatomical details of stratigraphically and geographically isolated specimens are taxonomically meaningful, particularly in the face of ontogenetic variation, and may only be resolved by the recovery of further, more mature lambeosaurine specimens from the Wapiti Formation.

\title{
Sourcing and radiocarbon dating mammoths (Mammuthus sp.) of British Columbia
}

\section{Laura Termes}

Department of Archaeology, Simon Fraser University, Burnaby, BC, V5A 1S6, Canada; laura_termes@sfu.ca

Mammoth remains in British Columbia (BC) are geographically dispersed across museum and private collections and there is no synthesis on the condition of these specimens, the species to which they belong, their provenience, their age, or to when they date. Mammoths in the Yukon Territory, Alberta and Washington State are well documented, but those from British Columbia are sparse, limiting our knowledge of western North American mammoth distribution.

To remedy this gap in our knowledge of Pleistocene megafauna, I have begun to create a comprehensive database of known mammoths in the province as a part of the BC Megafauna Project at Simon Fraser University. Seeking mammoths in private and public collections, this research will locate, record, and radiocarbon date mammoth specimens to produce an open-access map of mammoth distribution and temporal range. Any private collector sampled specimen will remain with the collector. The results will provide a comprehensive understanding of where and when mammoths lived on the BC landscape. The resulting temporal map could be used with glaciation maps to evaluate if a keystone species such a mammoth may be a tool for evaluating the presence of glacial refugia.

\section{Vertebrate Remains from the Late Cretaceous Brazeau Formation of the Alberta Foothills}

\author{
Aaron J. van der Reest ${ }^{1}, \mathrm{~S}$. Andrew DuFrane ${ }^{2}$, Alberto V. Reyes ${ }^{2}$, and \\ Philip J. Currie ${ }^{1}$ \\ ${ }^{1}$ Department of Biological Sciences, University of Alberta, Edmonton, AB, T6G 2E9, Canada \\ ${ }^{2}$ Department of Earth and Atmospheric Sciences, University of Alberta, Edmonton, AB, Canada
}

The Upper Cretaceous Brazeau Formation (early Campanian-early Maastrichtian) represents a regressive nearshore marine to proximal fluvial system. The formation outcrops along river cuts in the Alberta Rocky Mountain foothills and was heavily deformed by tectonic forces during the Eocene. Although no vertebrate remains have been previously described, several bones had been collected prior to 2017. During the late summer of 2017 and 2018 preliminary exploration into the Brazeau Formation throughout the Rocky Mountain Foothills from Sundre north to Hinton was conducted. Several partial dinosaur skeletons were found, and elements that were easy to collect are now housed at the University of Alberta. Additionally, no radiometric dating had been con- 
ducted on tephra from the Brazeau, so a concerted effort was put in to locate and sample ashes. A bonebed near Hinton was investigated and multiple dinosaur specimens were recovered from a small test pit, including a left postorbital diagnosed as Edmontosaurus regalis because of an enlarged postorbital fossa. This is the first diagnostic dinosaur element to have been collected from the Brazeau Formation. Two tephra beds stratigraphically 16.5 $\mathrm{m}$ above the bonebed yielded statistically indistinguishable weighted-average laser ablation zircon ${ }^{206} \mathrm{~Pb} /{ }^{238} \mathrm{U}$ dates of $69.9 \pm 0.4 \mathrm{Ma}$ and $69.9 \pm 0.3 \mathrm{Ma}$, suggesting that this is the youngest positively identified specimen of Edmontosaurus regalis currently known and potentially extending the temporal distribution of the taxon an additional 1 Myr. Edmontosaurus regalis is now known from both the late Campanian and early Maastrichtian. Additionally, it is proposed that Edmontosaurus regalis is not limited to warm and wet environments as previously proposed, but that the taxon inhabited a much wider paleotopographical and wider range of environments including those that are cool and dry.

\section{FreqMorph: model of morphological evolution with empirical character state frequencies}

\section{Oksana V. Vernygora}

Department of Biological Sciences, University of Alberta, Edmonton, AB, T6G 2E9, Canada; vernygor@ualberta.ca

In morphological phylogenetics, application of probabilistic methods (maximum likelihood and Bayesian inference) has long been a controversial subject due to apparent unrealistic assumptions of the available model of morphological evolution. Although several recent studies indicate that Bayesian inference outperforms traditional parsimony when applied to discrete morphological data, scepticism remains about its use. The major objections concern whether the constraints on the parameters used in a likelihood model describing an evolutionary scenario are applicable for morphological data. The explicit time-reversible Markov model (Mk) of morphological data evolution specifies an oversimplified evolutionary scenario with a single rate of character state substitutions and equal character state frequencies - assumptions which are almost never corroborated by empirical data sets. Recently, several suggestions have been proposed for overcoming some of the assumptions of the Mk model including implementation of asymmetrical rates of character state transitions and application of an existing Felsenstein 81 (F81) model for restriction site molecular data to analyse binary morphological data sets. However, development and implementation of new models of evolution, which would provide a more accurate estimation of the morphological evolution, are hindered by both an infinitely complex nature of the morphological trait evolution and computational power constraints.

Here, I present a model of morphological trait evolution, referred to as FreqMorph, which implements empirical character state frequencies and can be applied to binary and multistate characters. Contrary to the F81 model for molecular data, FreqMorph does not assume comparability of states across all characters in a data set and calculates frequencies for each individual character in a matrix. I test performance of the new model by analyzing empirical and simulated morphological data sets under traditional Mk model and FreqMorph. Model-fit of the two models was assessed using Akaike information criterion (AIC) and Bayes factor (BF). Accuracy of each method was measured using the Robinson-Foulds $(\mathrm{RF})$ distance for maximum clade credibility and majority rule consensus topologies. The major findings indicate that the new model is statistically consistent and has always higher model-fit values compared to the traditional Mk model. Accuracy of the topological reconstructions was significantly different between the two compared models; however, performance varied across different categories of data sets. Overall, results indicate that using empirical character state frequencies can improve accuracy of phylogenetic reconstructions, but high model fit values are not necessarily indicative of the higher accuracy. 


\section{Ontogenetic change in humeri of the ceratopsian dinosaur Pachyrhinosaurus lakustai}

\section{Rebekah M. Vice ${ }^{1}$ and Corwin Sullivan ${ }^{1,2}$}

${ }^{1}$ Department of Biological Sciences, University of Alberta, Edmonton, AB, T6G 2E9, Canada; vice@ualberta.ca

${ }^{2}$ Philip J. Currie Dinosaur Museum, Box 328, Wembley, AB, T0H 3S0, Canada; corwin1@ualberta.ca2;

The Pipestone Creek Bonebed, just outside Wembley, Alberta, has been an abundant source of disarticulated remains of the distinctive ceratopsian dinosaur Pachyrhinosaurus lakustai since its discovery in 1974. Since then the site has yielded hundreds of cranial and postcranial bones belonging to a minimum of 27 individuals, and representing ontogenetic stages ranging from juvenile to adult. As part of a larger study on the forelimb and pectoral girdle of $P$. lakustai, various humeri from the Pipestone Creek Bonebed were studied. These elements not only provide information on allometric changes in humeral morphology during growth, but can be used to link body mass to allometry. This can be done by inputting humeral circumference into multiple scaling equations to generate a body mass estimate for each humerus. Analysis of 14 P. lakustai humeri, ranging from $196 \mathrm{~mm}$ to 537 $\mathrm{mm}$ in length, showed that a suite of measurements (e.g., midshaft circumference, deltopectoral crest length and transverse width across the distal condyles) were all positively allometric (i.e., characterized by allometric coefficients greater than one) with respect to humeral length. This demonstrates that the humerus became more robust with growth and that features associated with muscle attachment became better developed. The largest allometric coefficients pertain to the widths of the distal condyles (coefficient of 1.3) and the proximal end of the humerus (1.2), indicating that these parameters increased in size more rapidly throughout growth than others considered in the analysis. Body mass estimates for the various individuals represented by the humeri in the sample ranged from 76 to $1690 \mathrm{~kg}$. These estimates were then compared to body mass estimates of other adult ceratopsids calculated using the same scaling equations. Based on these estimates $P$. lakustai were comparable in size to Chasmosaurus irvinensis (1600 kg) and notably larger than Chasmosaurus belli (1313 kg) and Arrhinoceratops brachyops $(987 \mathrm{~kg})$. The estimated body mass of Pachyrhinosaurus canadensis $(3287 \mathrm{~kg}$ ) is much larger than that of Pachyrhinosaurus lakustai, indicating considerable size variation within the genus. Histological evidence pertaining to juvenile humeri indicates in the first year of their lives P. lakustai grew to have a body mass of at least $76 \mathrm{~kg}$, which more than doubled before age $3(252 \mathrm{~kg})$. A 3-year-old individual sampled had an estimated body mass of $293 \mathrm{~kg}$, demonstrating that the rate of growth of P. lakustai drastically decreases at this age. However, these similar body masses may be due to a similarity in age with one individual at the end of its third year of life and the other at the beginning of its fourth year. Further histological sampling, particularly of larger humeri is expected to shed additional light on growth patterns in P. lakustai. 


\title{
New juvenile specimens of Gorgosaurus libratus provide insight into the cranial ontogeny of albertosaurine tyrannosaurids
}

\author{
Jared T. Voris ${ }^{1}$, Darla K. Zelenitsky ${ }^{1}$, François Therrien², Lawrence M. \\ Witmer', Ryan C. Ridgley ${ }^{3}$, and Philip J. Currie ${ }^{4}$ \\ ${ }^{1}$ Department of Earth Sciences, University of Calgary, Calgary, AB, T2N 1N4, Canada; jared.voris@ucalgary.ca; \\ dkzeleni@ucalgary.ca \\ ${ }^{2}$ Royal Tyrrell Museum of Palaeontology, Drumheller, AB, T0J 0Y0, Canada; francois.therrien@gov.ab.ca \\ ${ }^{3}$ Department of Biomedical Sciences, Heritage College of Osteopathic Medicine, Ohio University, Athens, OH, 45701, \\ USA; witmerl@ohio.edu, ridgely@ohio.edu \\ ${ }^{4}$ Department of Biological Sciences, University of Alberta, Edmonton, AB, T6G 2E9, Canada; phillip.currie@ualberta.ca
}

Previous studies on the ontogeny of tyrannosaurids have reported major differences in cranial morphology between juvenile and adult individuals but were often limited by the incomplete or disarticulated nature of available juvenile material. The recent discovery of two articulated juvenile skeletons of Gorgosaurus libratus provides the opportunity to assess previously unknown aspects of early tyrannosaurid ontogeny. With skull lengths of -500 $\mathrm{mm}$, the new individuals are approximately 50\% the size of the largest known Gorgosaurus and are the smallest articulated albertosaurine specimens recovered from North America. The new specimens exhibit several cranial features typical of juvenile tyrannosaurids, such as a low and elongate skull, absent or nascent cranial ornamentation, large circular orbits, mediolaterally compressed teeth, and weakly inflated paranasal sinuses. In addition, juvenile specimens possess a deeper braincase box, shorter preotic pendants, and shorter and uninflated paroccipital processes compared to adults. Most ontogenetic changes associated with the transition from "juvenile" to "adult" skull morphology appear to occur when individuals reach a skull length of 50\% to $70 \%$ that of the largest adult individual. However, several morphological changes occur later in ontogeny, after individuals reach a skull length of $90 \%$ of the largest individual. Despite the significant anatomical differences observed between juvenile and adult Gorgosaurus, some albertosaurine synapomorphies are present at all known ontogenetic stages (e.g., caudal ramus of postorbital does not reach caudodorsal margin of laterotemporal fenestra). The ontogenetically invariant nature of such synapomorphies therefore provides a means to differentiate juvenile albertosaurines from morphologically-similar, sympatric juvenile tyrannosaurines (e.g., Daspletosaurus). 


\title{
Osteological correlates indicate the existence of uncinate processes in fossil archosaurs
}

\author{
Yan-yin Wang ${ }^{1}$, Corwin Sullivan ${ }^{1,2}$, and Aaron R.H. LeBlanc ${ }^{1}$ \\ ${ }^{1}$ Department of Biological Sciences, University of Alberta, Edmonton, AB, T6G 2E9, Canada; yanyin@ualberta.ca; \\ corwin1@ualberta.ca; arl@ualberta.ca \\ ${ }^{2}$ Philip J. Currie Dinosaur Museum, Wembley, AB, T0H 3S0, Canada
}

Uncinate processes are barb-like or tab-like structures protruding posteriorly from the vertebral ribs. They have long been known to occur in ossified form in almost all birds and some closely related (i.e., pennaraptoran) non-avian dinosaurs, and in cartilaginous form in crocodilians and the lepidosaur Sphenodon. Many functional hypotheses for avian uncinates and associated muscles have been proposed (e.g. reinforcement of the rib cage, assistance in ventilation), but only the ventilatory hypothesis has obtained support from experimental evidence. Uncinates have not been documented in extinct archosaurs outside Pennaraptora, although potentially homologous mineralized flanges have been reported in a few ornithischian dinosaurs (e.g., intercostal plates in Othnielosaurus). However, the possibility exists that many or even most extinct archosaurs possessed cartilaginous uncinates, resembling those of crocodilians, which would be unlikely to be preserved in the fossil record. In order to address this problem, and provide anatomical information about the evolution of the ventilatory system across Archosauria, we collected data from the ribs of extant and extinct archosaurs, to identify potential morphological correlates of uncinate attachments.

In well-mature individuals of at least some bird species (e.g., Struthio camelus), the uncinates are completely fused to the ribs, despite ossifying from a distinct centres. In extant crocodilians and in birds without occurrence of fusion, however, removal of an uncinate process from the corresponding rib leaves a rugose, concave scar on the posterior/posteromedial margin of the rib. We interpret similar scarring on multiple ribs of fossil crocodilians (e.g., Penghusuchus pani) and non-avian dinosaurs, including ceratopsians and tyrannosaurids (e.g., Daspletosaurus torosus and Gorgosaurus libratus) as evidence that cartilaginous uncinates were present in these taxa. We also identified one parasuchian rib and one aetosaur rib displaying potential uncinate scars with the expected rugose, concave morphology, although these isolated cases stand in need of confirmation from additional specimens.

Histological data were also collected from an adult Caiman crocodilus and a juvenile domestic turkey (Meleagris gallopavo). In both the turkey and C. crocodilus, the uncinate is connected to the rib by dense fibrous connective tissues. At the position of the uncinate scar, the cortical bone of the rib possesses especially numerous Sharpey's fibres, possibly for attachment of the uncinate. Articular cartilage covers the anterior margin of the hyaline cartilage in the turkey uncinate, and is in turn bound to the rib by the fibrous connective tissues; this articular cartilage is absent in C. crocodilus. The presence of a fibrous connection between the uncinate and the rib cortex in extant archosaurs indicates that this attachment might be identifiable in histological sections of fossil ribs as well, because the fibrous connective tissues often have the potential to become mineralized, and ultimately fossilized.

Our results suggest that the presence of uncinates can be consistently identified, using a combination of macroscopically apparent scarring and histological features in archosaurs. The discovery of uncinates in multiple fossil archosaurs, combined with the extant phylogenetic bracketing suggests that uncinates may have been a widespread feature through out Archosauria, and may therefore have been utilized as part of the ventilatory system well before the advent of birds. 


\section{Ontogenetic niche shifts in megaherbivorous dinosaurs of the Late Cretaceous of North America}

\section{C.A. Wyenberg-Henzler ${ }^{1}$ and Jordan C. Mallon ${ }^{2}$}

${ }^{1}$ Carleton University, Ottawa, ON, K1S 5B6, Canada; taiawh626@gmail.com

${ }^{2}$ Canadian Museum of Nature, PO Box 3443, Station D, Ottawa, ON, K1P 6P4, Canada; JMallon@nature.ca

Previous research concerning the megaherbivorous dinosaur assemblage (e.g., ankylosaurs, hadrosaurids, ceratopsids) of the middle to late Campanian Dinosaur Park Formation of Alberta has shown that species coexistence was facilitated, at least partly, by dietary niche partitioning. However, work to date has focused primarily on adult ecology without consideration of how niches may have changed through ontogeny. It has been suggested, based on body size similarity, that juvenile megaherbivorous dinosaurs competed with adults of small-bodied ornithischian species (i.e., thescelosaurids, pachycephalosaurids, and leptoceratopsids). However, this hypothesis assumes otherwise similar ecomorphological adaptations of the skeleton, which has not yet been tested.

To address these deficiencies, we assessed the potential for ontogenetic niche shifts in hadrosaurids and ceratopsids, and the associated impacts on the surrounding herbivore community, using cranial morphometrics and an added measure of beak shape. Preliminary analysis indicates that, other than increasing size, adult hadrosaurids and ceratopsids primarily differ from juveniles in their possession of longer rostra. Longer rostra may have facilitated browsing by allowing the eyes to be kept a safe distance away from protruding twigs and focused on possible threats, as in many ungulates today. Alternatively, lengthening of the face may occurred to accommodate ontogenetic lengthening of the tooth battery. Both hadrosaurids and chasmosaurines overlap minimally, but not significantly, in morphospace, and this overlap is manifested equally throughout ontogeny. There is some overlap of small ornithischians with juvenile hadrosaurids and ceratopsids, but sample size is presently too small to determine its significance. The proximity of these smaller groups to juvenile megaherbivores in ecomorphospace suggests some potential for competition, but more data are needed. This research is the first to assess the impact of ontogenetic niche shifts on the structure of dinosaur communities. 


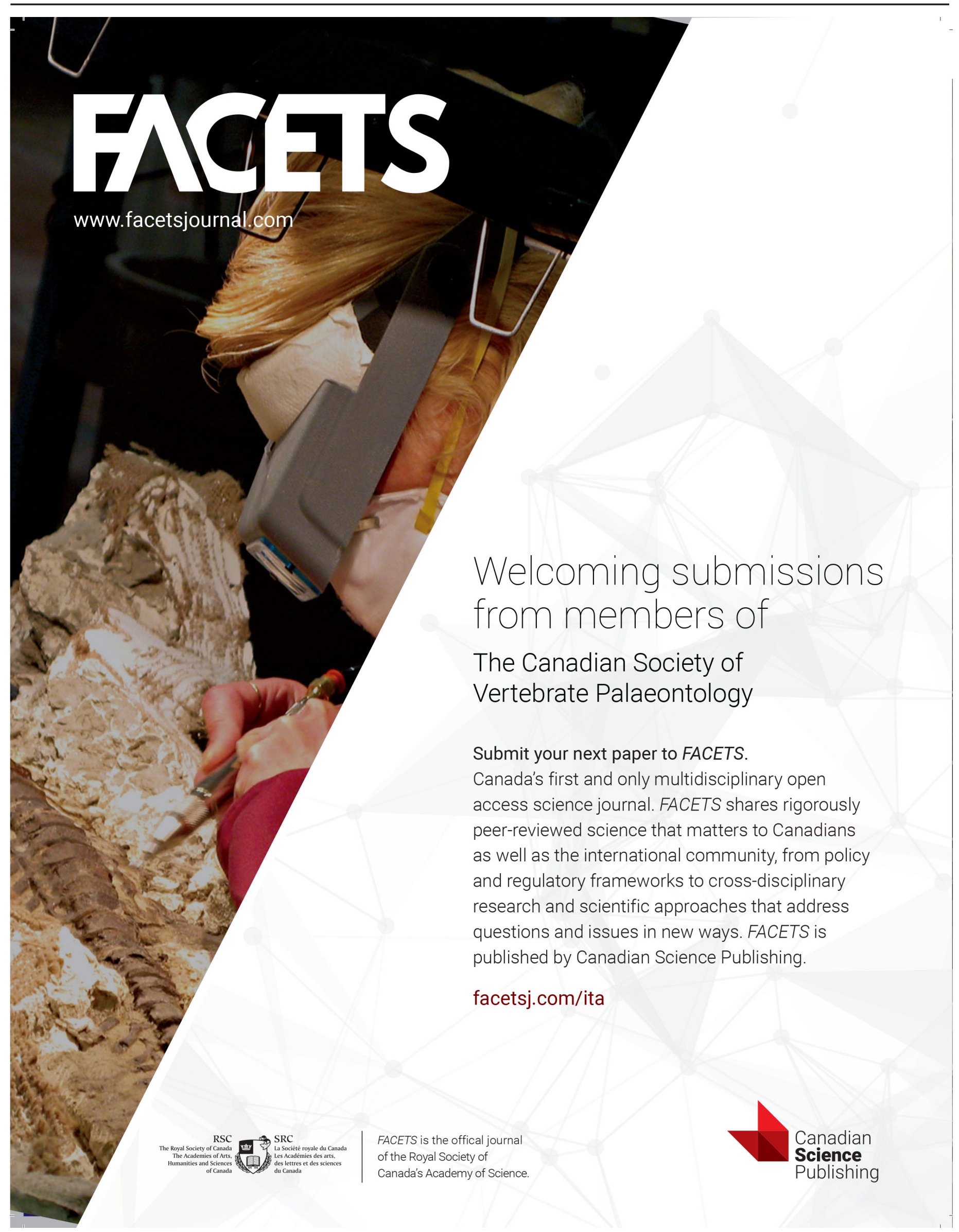




\section{Thanks to our reviewers:}

Gregory Funston

Danielle Fraser

Matthew Rhodes

Thomas Cullen

Aaron LeBlanc

Hallie Street

Mark Powers

Ashley Reynolds

Kirstin Brink

Caleb Brown

Rebekah Vice

Samantha Hamilton

Ilaria Paparella

Victoria Arbour

Jordan Mallon 
Thanks to our sponsors for CSVP 2019

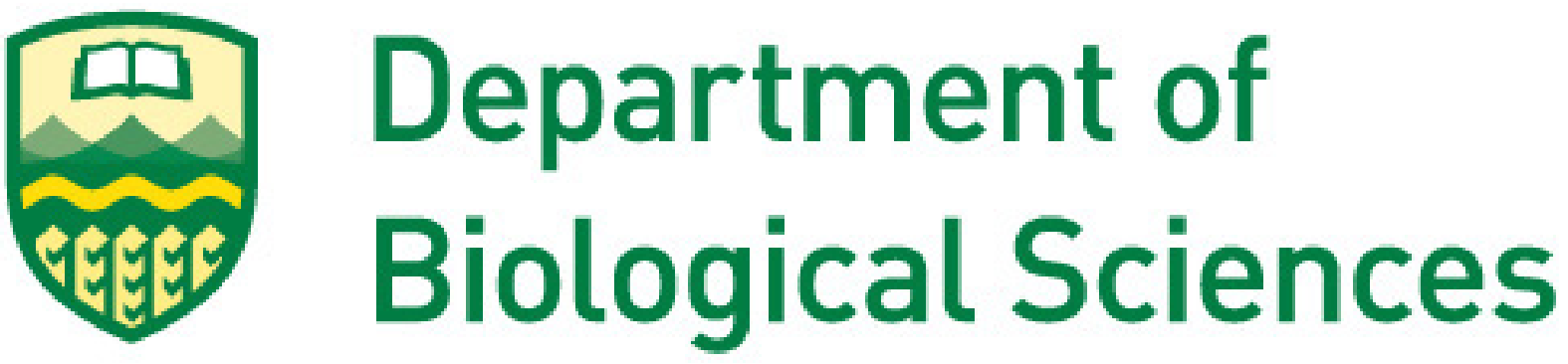

UNIVERSITY OF ALBERTA
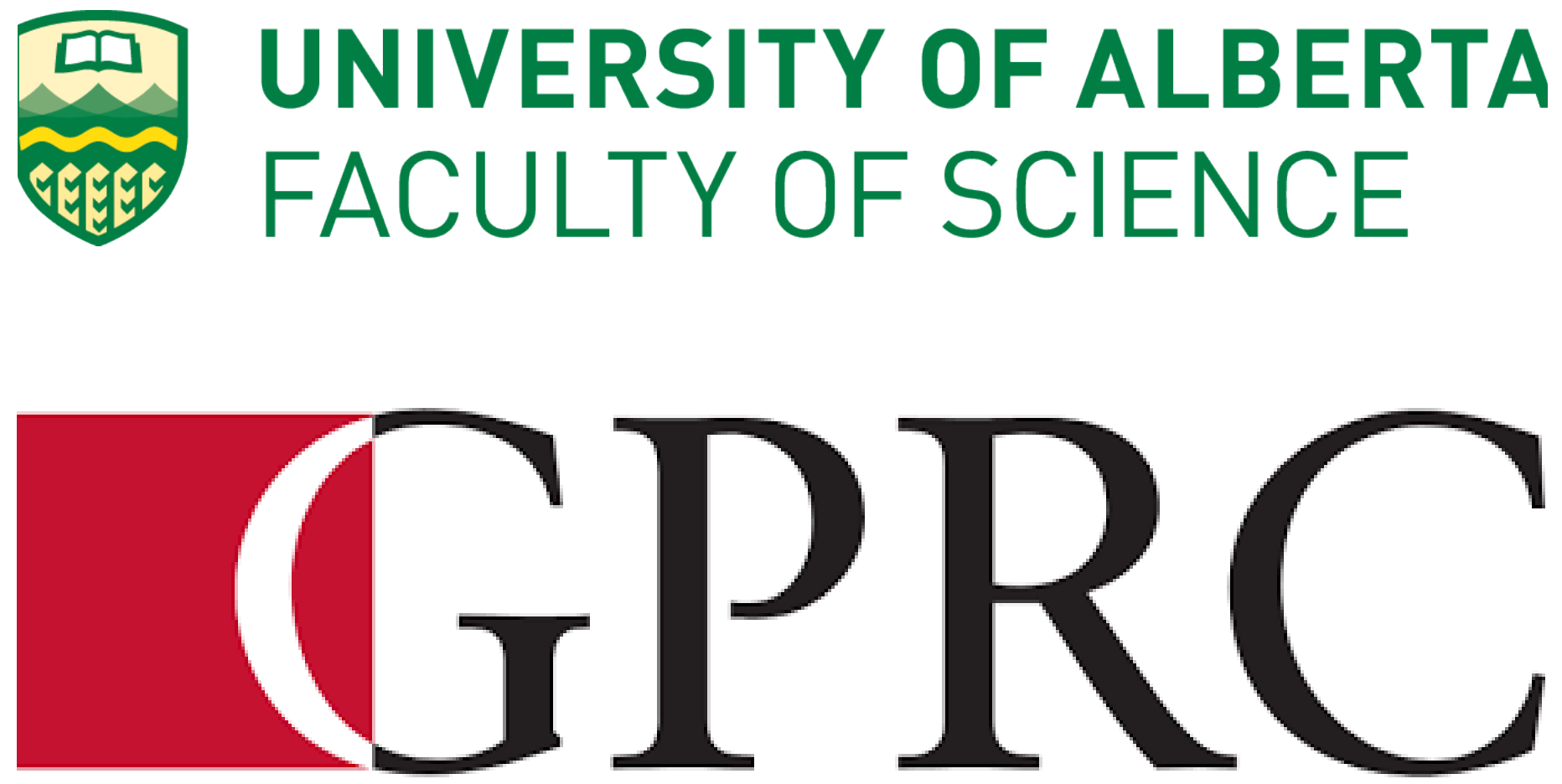

\section{SCIENCE EQUIPMENT CORP.}

